\title{
UNA PROPUESTA METODOLÓGICA PARA EL ESTUDIO DE LA METALURGIA PREHISTÓRICA: EL CASO DE GORNY EN LA REGIÓN DE KARGALY (ORENBURG, RUSIA)
}

\author{
A METHODOLOGICAL PROPOSAL TO STUDY \\ THE PREHISTORICAL METALLURGY: \\ THE CASE OF GORNY IN THE KARGALY REGION \\ (ORENBURG, RUSSIA)
}

SALVADOR ROVIRA $(*)$

\section{RESUMEN}

Los trabajos arqueológicos de campo en el sitio de Gorny (habitado durante los siglos XVII-XV AC) han proporcionado una importante colección de materiales relacionados con actividades metalúrgicas (minerales, escorias, restos de fundición y objetos metálicos). En su estudio analítico se han empleado diversas técnicas de laboratorio (microscopía electrónica de barrido, espectrometría por fluorescencia de rayos $\mathrm{x}$, metalografía) cuyos resultados caracterizan una metalurgia de rasgos primitivos que parte de la fundición directa de minerales oxídicos de cobre. Los objetos de metal, fundidos en molde, eran terminados mediante trabajos de forja y aplicación, en ocasiones, de tratamientos térmicos.

Con la ayuda de experimentos de fundición in situ se ha reproducido el proceso prehistórico, permitiendo de ese modo establecer variables económicas tales como el rendimiento en cobre de las fundiciones y el consumo de combustible, a partir de las cuales se elaboran modelos teóricos estimativos de la producción metalúrgica y su impacto en el medio ambiente.

\footnotetext{
ABSTRACT

Archaeological field-work realised at the site of Gorny (occupied from 1700 to 1400 BC) has furnished an important collection of materials related to metallurgical activities (ores, slags, by-products and copper objects). These

(*) Museo Arqueológico Nacional. Dpto. de Conservación. Serrano, 13. 28001 Madrid. Correo electrónico: srl@man.es.

El artículo fue remitido en su versión final el 15-XI-99.
}

have been analyzed by a variety of instrumental techniques (scanning electron microscopy, $X$-ray fluorescence spectroscopy and metallography). The results show that metallurgy was a primitive one that worked oxidised copper ores by a non-slagging smelting process. Cast objects were finished by cold hammering and, on some occasions, annealing.

A replication of the prehistoric technology has been achieved by means of on-site smelting experiments. Thus, economic variables such as the efficiency of copper recovery and charcoal consumption have been evaluated and, using them, theoretical models of copper production and its behavioural impact have been constructed.

Palabras clave: Metalurgia. Escorias. Minerales. Cobre. Edad del Bronce. Cultura Srubnaia. Rusia. Metalurgia experimental.

Key words: Metallurgy. Slags. Ores. Copper. Bronze Age. Srubnaya Culture. Russia. Smelting experiments.

\section{INTRODUCCIÓN}

El presente estudio es uno de los frutos del proyecto de investigación PS95-0031, El inicio de la economía productiva en la gran estepa eurasiática y su impacto en el medio ambiente: ¿catástrofes ecológicas en las estepas?, dirigido por la Dra. M. ${ }^{2}$ Isabel Martínez Navarrete (CSIC) y financiado por la DGICYT entre 1996 y 1999. Pero las relaciones con el equipo ruso que dirige el Prof. Ye. N. Chernyj, del Instituto de Arqueología de la Academia Rusa de Ciencias (Moscú), datan de mucho más 
atrás. De hecho mi primer contacto con la estepa de Kargaly se remonta a la campaña de 1993, y desde entonces me he sentido fascinado por su inmensa cuenca minera, con sus miles de pozos abiertos en la llanura como pequeños cráteres.

Entre las primeras noticias sobre las expediciones a Kargaly publicadas fuera de Rusia figuran los artículos de Chernykh (1994, 1995), en los que ya se planteaban hipótesis catastrofistas acerca del impacto ecológico de la metalurgia del cobre. En aquellos momentos el conocimiento real de las características de dicha metalurgia era más bien escaso y parcial, y hasta unos años más tarde no pudimos ofrecer resultados más concretos (Chernykh y Rovira, 1998).

El trabajo arqueológico de campo se ha concentrado durante los últimos años en el sitio denominado Gorny, donde se ha excavado un complejo espacio de habitación y taller metalúrgico. Las dataciones radiocarbónicas obtenidas a lo largo de la secuencia estratigráfica permiten distinguir cuatro fases de habitación dentro del intervalo calibrado que va de 1690 a 1410 a.C, según Chernyj et alii (1999: 98-99, 101) (1):

Fase A, desde comienzos hasta finales del siglo XVII a.C.

Fase B-1, desde finales del siglo XVII hasta finales del XVI a.C.

Fase B-2, desde finales del siglo XVI hasta mediados del siglo $\mathrm{XV}$ a.C.

Fase B-3, desde mediados hasta finales del siglo XV a.C.

Esta división en fases tiene mucho que ver con la organización del hábitat de Gorny. Así, la FaseA se caracteriza por muchas pequeñas viviendas excavadas en el suelo hasta unos $2 \mathrm{~m}$ de profundidad, auténticas fosas de 1,4 a $4 \mathrm{~m}^{2}$ de superficie. La Fase B1 corresponde a la construcción y habitación de una gran vivienda-taller que ocupa la mayor parte del área excavada (unos $700 \mathrm{~m}^{2}$ ). La Fase B-3 se inicia con la destrucción de la gran vivienda, cuyas ruinas siguieron sirviendo de refugio a la población. Finalmente, en la Fase B-3 no se distingue claramente el tipo de vivienda utilizado y está atestiguada por el relleno de las fosas anteriores con grandes cantidades de materiales de desecho de este último periodo de ocupación del lugar. Estas fases corresponden al Bronce Final de la zona, cultura Srubnaia.

(1) A efectos de la cronología absoluta se han tomado las calibraciones en el intervalo de 1 sigma. En el mencionado trabajo de Chernykh et alii (1999) las fases se denominan utilizando la numeración romana (I a IV). Con posterioridad se ha modificado la nomenclatura, pero no su contenido.
La explotación de los recursos mineros de Kargaly en época pre-Srubnaia está sujeta a discusión. Mientras hay quien opina que la antigüedad no debe ser mucho mayor, rechazando su beneficio en el Calcolítico y Bronce Antiguo (N. Ryndina, comunicación personal), el hallazgo de un enterramiento juvenil en fosa, cubierto por la estructura de un kurgan arrasado por los movimientos de tierra derivados del trazado de un camino rural en Pershin, a pocos kilómetros de Gorny, y en cuyo ajuar apareció un molde de fundición y un hacha plana, permite abrigar la esperanza de encontrar ocupaciones algo más antiguas que las del Bronce Final (Chernyj, campaña de urgencia efectuada en 1997, comunicación personal).

En cualquier caso, Kargaly es uno de esos pocos grandes centros minero-metalúrgicos, junto con Feinan (Jordania) y Timna (Israel), de capital importancia para el estudio de la producción de cobre deśde tiempos prehistóricos hasta épocas modernas. Es más singular, si cabe, que los sitios mencionados porque, como se verá más adelante, la producción estimada de mineral y de metal arroja cifras enormes conseguidas con una tecnología muy sencilla (esta es la característica diferenciadora) que apenas evoluciona hasta la fase preindustrial rusa (siglo XVIII AD). Su particular interés para nosotros estriba en las posibilidades de comparación con la metalurgia prehistórica de la Península Ibérica, también de rasgos sencillos pero con un nivel de producción muy inferior. Sin duda nos hallamos ante dos áreas de una periferia con rasgos muy personales, aunque no tan distintos en términos tecnológicos.

\section{METODOLOGÍA}

Tras el primer contacto con la inmensa región minera de Kargaly fuimos conscientes de que nuestros objetivos arqueometalúrgicos debían limitarse o atemperarse al ritmo de la excavación arqueológica, sin por ello dejar de lado la prospección de los alrededores y, si había oportunidad, de alguna mina.

Las posibilidades de estudio se centraron en Gorny, participando en los trabajos de excavación propiamente dichos, en la recuperación de materiales pirometalúrgicos y en el estudio de las estructuras que se iban desenterrando. El conocimiento de estos aspectos es básico para lograr una buena interpretación arqueometalúrgica del conjunto (Rovira, 1992).

T. P., 56, n. ${ }^{\circ} 2,1999$ 
Los objetivos globales de la investigación se han enfocado hacia el establecimiento de los procesos de obtención de cobre a partir de los minerales locales y de los tratamientos de taller para la producción de objetos de metal. Para poder llevar a cabo el estudio se fueron seleccionando muestras de materiales interesantes (escorias, minerales, restos de fundición y fragmentos de objetos metálicos), en unos casos personalmente en la propia excavación y en otros casos por los técnicos rusos al hacer la revisión de cada campaña arqueológica. Este procedimiento de muestreo es adecuado para resolver problemas tecnológicos, pues se eligen las muestras que mejor respuesta pueden dar a las cuestiones concretas planteadas como hipótesis de trabajo. Es menos conveniente para analizar procesos de cambio, pero aquí tropezábamos con un problema y es que las correlaciones crono-estratigráficas no se han podido fijar hasta el último momento por el equipo ruso (en 1999). En cualquier caso, intuíamos que este sería un problema menor pues los restos arqueometalúrgicos mostraban una gran homogeneidad en todas las fases de la excavación, avalada por los resultados analíticos que íbamos obteniendo desde 1995, aunque resultara que no todas las fases del yacimiento estuvieran igualmente representadas en cuanto a cantidad de muestras.

Hemos tenido, por otro lado, las limitaciones presupuestarias que impone todo proyecto de investigación y ello ha obligado a ser particularmente meticulosos para no exceder lo presupuestado en el capítulo de análisis y, al mismo tiempo, obtener los resultados apetecidos. También había que tener en cuenta las dificultades aduaneras para la salida de Rusia de este material científico, a pesar de todo el apoyo oficial prestado por la Academia Rusa de Ciencias.

Con todo, el hecho cierto es que hemos podido estudiar un conjunto relevante de materiales que supera, con mucho, lo habitual en los estudios arqueometalúrgicos. Los trabajos de laboratorio han sido efectuados en Madrid, coordinados desde el Departamento de Conservación del MuseoArqueológico Nacional, utilizando las siguientes técnicas instrumentales:

- Microscopía óptica (MO), para la observación de estructuras y fases en metales, minerales y escorias. Se ha utilizado un microscopio metalográfico invertido Reichert MeF3A y un microscopio convencional Reichert Polyvar, del Laboratorio del Museo de América.

- Microscopía electrónica de barrido (MEB) para la observación y análisis semicuantitativo (vía ZAF) de estructuras y fases en metales, minerales y escorias. Se ha utilizado un equipo Philips XL 30, con fuente de wolframio, detectores de electrones secundarios y retrodispersados, alcanzando un vacío de $3 \times 10^{-6}$ torr. El análisis químico es por energía dispersiva de rayos $\mathrm{X}$, con detector de $\mathrm{Si}$-Li y analizador DX4i de EDAX. El equipo ha sido operado por Esperanza Salvador, técnico especialista del Servicio Interdepartamental de Investigación de la Universidad Autónoma de Madrid.

- Espectrometría por fluorescencia de rayos X (energía dispersiva), para el análisis elemental cualitativo y semicuantitativo de elementos pesados en minerales y escorias. Se ha utilizado el espectrómetro multicanal Kevex Mod. 7000, con detector de $\mathrm{Si}$-Li y fuente de ${ }^{241} \mathrm{Am}$, del proyecto Arqueometalurgia de la Península Ibérica (2), instalado en el Instituto de Patrimonio Histórico Español.

Con los dátos analíticos obtenidos se ha podido reconstruir el proceso metalúrgico de obtención de cobre en Gorny y su posterior empleo para elaborar lingotes y objetos de metal. Pero dado que uno de los objetivos del proyecto DGICYT PS95-0031 era evaluar el impacto ecológico de la explotación minero-metalúrgica en Kargaly, se hacía imprescindible realizar experimentos de fundición de minerales de cobre usando las técnicas deducidas a partir del análisis de los restos arqueológicos. De ese modo podríamos valorar parámetros tales como el consumo de carbón, duración y rendimiento de las operaciones, etc., con los que trazar modelos estimativos. Se llevaron a cabo cinco experimentos con minerales y dos con el metal obtenido, siendo analizados los materiales con las mismas técnicas instrumentales aplicadas a los arqueológicos.

El empleo de la vía experimental para discutir y comprender mejor la metalurgia prehistórica no es ninguna novedad, si bien el número de experimentos realizados es relativamente pequeño (Tylecote y Merkel, 1985). Sin embargo, raramente se ha utilizado esta vía para elaborar modelos globales de producción ni, en términos más modestos pero de gran interés, para comparaciones directas de rendimientos deducidos a partir de materiales arqueológicos y de experimentos. En esta situación ha influi-

(2) Este proyecto, iniciado en 1982 bajo la dirección de los profesores Manuel Fernández-Miranda y Germán Delibes de Castro ha contado con diversas fuentes de financiación de sus distintos subproyectos. El último ha sido el DGICYT (I+D) PB920315 . 


\begin{tabular}{|c|c|c|c|c|c|c|c|c|c|c|c|c|c|}
\hline Análisis & $\mathrm{N}^{\circ}$ Invent. & Fase & Región analizada & $\mathrm{FeO}$ & $\mathrm{Al}_{2} \mathrm{O}_{3}$ & $\mathrm{SiO}_{2}$ & $\mathrm{CaO}$ & MgO & $\mathrm{BaO}$ & $\mathrm{K}_{2} \mathrm{O}$ & $\mathrm{TiO}_{2}$ & $\mathrm{CuO}$ & SO \\
\hline EXGOR5/m1 & & Sup. & Análisis general & 0,96 & 7,5 & 65.3 & 1.2 & 0 & 0,34 & 1.1 & 0 & 23.1 & 0.26 \\
\hline EXGOR5/m2 & & Sup. & Análisis general & 1,8 & 6,8 & 53,2 & 1,6 & 0 & 2,9 & 1,1 & 0,57 & 30,7 & 1,2 \\
\hline EXGOR5/m2-1 & & Sup. & Veta baritina & 1,9 & 1,1 & 6,3 & 1,0 & 0,3 & 62.1 & 0,8 & 3.5 & 4.0 & 19.1 \\
\hline EXGOR5/m2-2 & & Sup. & Granos gris claro & 19,0 & 11,8 & 38,1 & 1.2 & 9.2 & 0.74 & 0.4 & \begin{tabular}{l|l|}
0,62 \\
\end{tabular} & 18.2 & 0.68 \\
\hline EXGOR5/m2-3 & & Sup. & Granos casi blancos & 4,0 & 5,2 & 44,5 & 2,1 & 1,3 & 1,1 & 0,43 & 0 & 41,2 & 0 \\
\hline EXGOR $5 / \mathrm{m} 3$ & & Sup. & Análisis general & 0,75 & 6,2 & 55,8 & 1,0 & 0 & 0.72 & \begin{tabular}{l|l}
0.87 \\
\end{tabular} & 0 & 34,1 & 0.57 \\
\hline EXGOR5/m4 & & Sup. & Análisis general & 2,2 & 6.7 & 47.6 & 1.6 & 0.69 & 0.58 & \begin{tabular}{l|l}
0.89 \\
\end{tabular} & 0,37 & 38.9 & 0.44 \\
\hline EXGOR5/m5 & & Sup. & Análisis general & 1,0 & 8,6 & 60,5 & 1,5 & 1,3 & \begin{tabular}{l|l}
0,67 \\
\end{tabular} & 0,97 & 0.54 & 24,6 & 0,33 \\
\hline EXGOR5/m6 & & Sup. & Análisis general & 1,2 & 7,7 & 55,7 & 1,3 & 0.65 & 8,2 & 1.4 & 0 & 20.2 & 3.7 \\
\hline GOR-m01 & $5127-\mathrm{c} / 4$ & B-3 & Análisis general & 0.78 & 1,1 & 7.6 & 0,69 & 0 & 1,4 & 0,05 & 0 & 82.7 & 0 \\
\hline GOR-m02 & $5127-\mathrm{c} / 4$ & B-3 & Análisis general & 2,3 & 6,6 & 44,9 & 1,3 & 0,26 & 0,52 & 1,2 & 0 & 41,6 & 0 \\
\hline GOR-m03 & $5127-\mathrm{a} / 5$ & B-3 & Análisis general & 2,4 & 6,4 & 32,3 & 0,92 & 0,36 & 0.35 & 0,53 & 0 & 50.5 & 0 \\
\hline GOR-m04/1 & $5127-a / 5$ & B-3 & Análisis general & 7,2 & 4,5 & 21,0 & 1,3 & 0 & \begin{tabular}{l|l}
0.19 \\
\end{tabular} & \begin{tabular}{l|l|}
0.36 \\
\end{tabular} & 0 & 49.7 & 0 \\
\hline GOR-m04/2 & $5127-a / 5$ & B-3 & Análisis general & 6,5 & 7,2 & 55,2 & 1,3 & 0 & \begin{tabular}{l|l|}
0,62 \\
\end{tabular} & 1,2 & 0 & 27,7 & 0 \\
\hline GOR-m05 & & Sup. & Análisis general & \begin{tabular}{l|l}
3,4 \\
\end{tabular} & 1,6 & 8,3 & 0,2 & 0 & 10.4 & 0.4 & 0 & 57.5 & 16.7 \\
\hline GOR-m06/1 & & Sup. & Análisis general & \begin{tabular}{l|}
1,7 \\
\end{tabular} & 5,3 & 25,1 & 0,74 & 1.2 & \begin{tabular}{l|l}
0.95 \\
\end{tabular} & 1,3 & 0 & 63.5 & 0.36 \\
\hline GOR-m06/2 & & Sup. & Capa gris claro & 0,9 & 2,0 & 8,3 & 0,37 & 0,75 & 1,4 & \begin{tabular}{l|l}
0.37 \\
\end{tabular} & 0 & 85.2 & 0,67 \\
\hline GOR-m06/3 & & Sup. & Capa gris claro & 0,41 & 1,5 & 4,5 & 0,5 & 0,88 & 1.6 & 0,36 & 0 & 89.1 & 4.5 \\
\hline GOR-m06/4 & & Sup. & Capa oscura & 5,4 & 11.6 & 55,6 & 1,9 & 2.1 & 2.5 & 2.6 & 0 & 17.6 & 0.58 \\
\hline GOR-m07 & & Sup. & Análisis general & 2,5 & 5,8 & 28,8 & 0,79 & 0 & 0,68 & 0.97 & 0 & 58,8 & 1,5 \\
\hline GOR-m08/1 & & Sup. & Capa oscura & 0,97 & 0 & 0 & 0 & 0 & 0.98 & 0 & 0 & 97.8 & 0.3 \\
\hline GOR-m08/2 & & Sup. & Cristales poligonales & 0,8 & 0 & 0 & 0 & 0 & 0,9 & 0 & 0 & 76,3 & 22,1 \\
\hline GOR-m08/3 & & Sup. & Capa gris continua & 1,2 & 0 & 0 & 0 & 0 & 57,8 & 0 & 0 & 19,7 & 21,4 \\
\hline GOR-m08/4 & & Sup. & Análisis general & 0,7 & 0 & 0 & 0 & 0 & 9.8 & 0 & 0 & 77,6 & 11,9 \\
\hline GOR-m09 & & Sup. & Análisis general & 3,1 & 1,3 & 6,0 & 0.3 & 0 & 2.7 & 0.4 & 0 & 67,0 & 19.3 \\
\hline GOR-m10 & & Sup. & Análisis general & 2,3 & 6,8 & 39,1 & 1,2 & 1,3 & 0,95 & 1,1 & 0 & 46,4 & 0,93 \\
\hline GOR-ml1 & & Sup. & Análisis general & \begin{tabular}{l|l|}
0,64 \\
\end{tabular} & 4,8 & 53,0 & 0,91 & 0.5 & 1.5 & 1.3 & 0 & 34.2 & 3.15 \\
\hline GOR-m12/1 & & Sup. & Análisis general & \begin{tabular}{l|}
1.7 \\
\end{tabular} & 10 & 60,3 & 3,0 & 1,3 & 2,0 & \begin{tabular}{l|l}
1,9 \\
\end{tabular} & 0 & 19.1 & 0.6 \\
\hline GOR-m12/2 & & Sup. & Capa más clara & \begin{tabular}{l|l}
4,2 \\
\end{tabular} & 11 & 56,4 & 2,6 & 1,6 & 2,1 & \begin{tabular}{l|l}
2,2 \\
\end{tabular} & 0 & 19,4 & 0,5 \\
\hline GOR-m13/1 & & Sup. & Análisis general & 1,9 & 9,1 & 59,0 & 1,4 & 0.7 & 1.2 & 1.5 & 0 & 25.3 & 0 \\
\hline GOR-m13/2 & & Sup. & Inclusiones claras & 0 & 0 & 0 & 0 & 0 & 0 & 0 & 0 & 100 & 0 \\
\hline
\end{tabular}

Tab. 1. Análisis de minerales de cobre de Gorny (Microsonda MEB, \% en peso; Sup.= Superficie).

do la poca atención prestada antes a los procesos más antiguos de obtención de metal, poco o nada convencionales, descubiertos y descritos en los últimos años (Rovira, 1989; Hauptmann et alii, 1996; Rehren, 1997 (3)), y que están reconduciendo, tanto los estudios de escorias al establecer nuevas categorías, como la propia experimentación (Ambert, 1998). Por otro lado, la estimación de la producción en los grandes centros minero-metalúrgicos se efectúa habitualmente ( $\mathrm{y}$ de forma bastante precisa) a partir del cubicado de los escoriales, método que, como se verá seguidamente, no es aplicable en Kargaly.

(3) Rehren, T. (1997): "Fourth millennium BC copper metallurgy in northern Jordan: The evidence from Tell esh-Shuna". En T. Rehren: Tiegelmetallurgie. Tiegelprozesse und ihre Stellung in der Archäometallurgie. Tesis de Habilitación inédita. Universidad de Freiberg. Bochum: 51-60.
El material arqueometalúrgico de Gorny, por las peculiaridades detectadas en los estudios preliminares (Chernykh y Rovira, 1998), hacía imprescindible la experimentación como condición sine quae non para avanzar en estudios de verdadero alcance que realmente pudieran integrarse en un proyecto pluridisciplinar cuyas conclusiones rebasaran la simple y habitual yuxtaposición de conocimientos.

\section{LOS MINERALES DE KARGALY}

El complejo minero de Kargaly se extiende formando una gran cuenca de superficie aproximadamente ovalada, de unos $50 \mathrm{~km}$ de eje mayor y unos $10 \mathrm{~km}$ de anchura máxima. Se halla situado al norte de la ciudad de Orenburg, en las estribaciones me- 


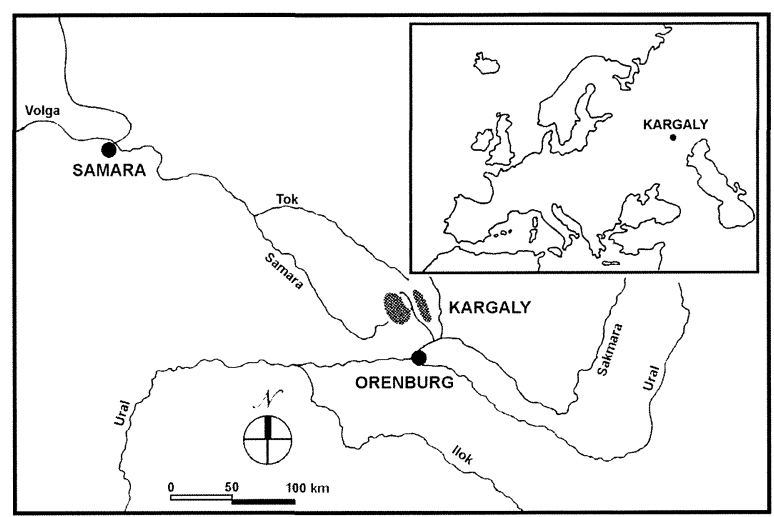

Fig. 1. Localización geográfica de la región de Orenburg (República Federativa Rusa).

ridionales de los Urales, en la línea imaginaria de frontera entre Europa y Asia (Fig. 1). El paisaje es el típico de la estepa rusa, en este caso una llanura surcada por pequeños valles abiertos por los cursos fluviales del Kargalka y el Yangiz, afluentes del Ural, cuyo efecto erosivo ha generado un relieve suavemente ondulado (Lám. I).

El substrato rocoso está constituido por series litológicas de areniscas rojas y grises del Permiano. En un determinado periodo de la fase formativa de estas rocas se produjeron arrastres aluvionares de minerales de cobre que con el tiempo formaron bolsadas, lentejones e impregnaciones de cuprita, malaquita y azurita, de tamaño variable, desde unos pocos centímetros hasta una decena de metros, así como sustituciones fibrosas en lechos con madera fosilizada. Se trata, pues, de un criadero del ciclo sedimentario. La capa metalífera yace en las areniscas grises, acompañada con frecuencia por conglomerados calizos y ferruginosos en sus niveles basales. Para mayor información.véase Chibilev (1996) (4).

Las areniscas de Kargaly se encuentran perforadas por miles de pozos y cientos de kilómetros de galerías cuya maraña está en su inmensa mayor parte sin explorar (Lám. II). Según Ye. N. Chernyj (comunicación personal), durante la Edad del Bronce se debieron abrir muchos de ellos, pues según las fuentes escritas, cuando en el siglo XVIII se re-descubre la riqueza minera de esta zona, abandonada misteriosamente a finales del Bronce Final y apenas explotada durante la Edad Media, los nuevos mineros se limitaron a seguir y ampliar los trabajos

4) Agradecemos al Dr. V. Poutchkov (Ufimian Scientific Center, Bashkiria, Rusia) su amabilidad al traducirnos al inglés las partes del libro original ruso concernientes a las minas de Kargaly.

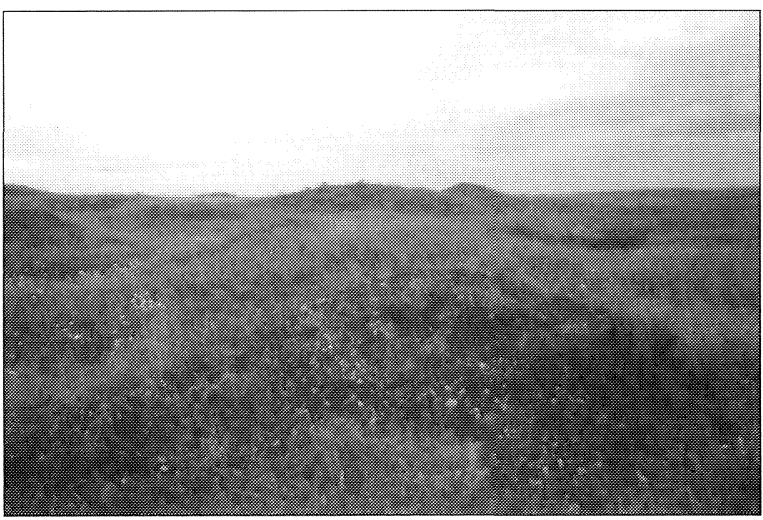

Lám. I. Paisaje de la estepa de Kargaly con los característicos amontonamientos formados por los vacíes de las minas.

efectuados por sus predecesores. Esta segunda etapa comenzó en 1745 y duró hasta 1900 (Chernij, 1995: 34-35), situándose las fundiciones más cercanas en el territorio de Bashkiria, a más de 300 $\mathrm{km}$ de distancia, en el área boscosa de los Urales del Sur.

A lo largo de las sucesivas campañas de trabajo en el sitio de Gorny se ha ido formando una colección de muestras de mineral, unas halladas en los sedimentos de la propia excavación arqueológica y otros en los vacies de las minas del entorno inmediato. Los análisis generales (Tab. 1) dan una riqueza en cobre (analizado como $\mathrm{CuO}$ ) que oscila entre el $20 \%$ y el $80 \%$, es decir, cuprita prácticamente pura e impregnaciones en arenisca con leyes de cobre muy variadas.

La ganga está compuesta principalmente por la roca encajante (sílice) y silicato de aluminio, en la que se encuentran también compuestos de calcio, magnesio y potasio. El contenido en óxido de hierro es, en general, inferior al $5 \% \mathrm{FeO}$. El bario y el azufre son consecuencia de la presencia diseminada

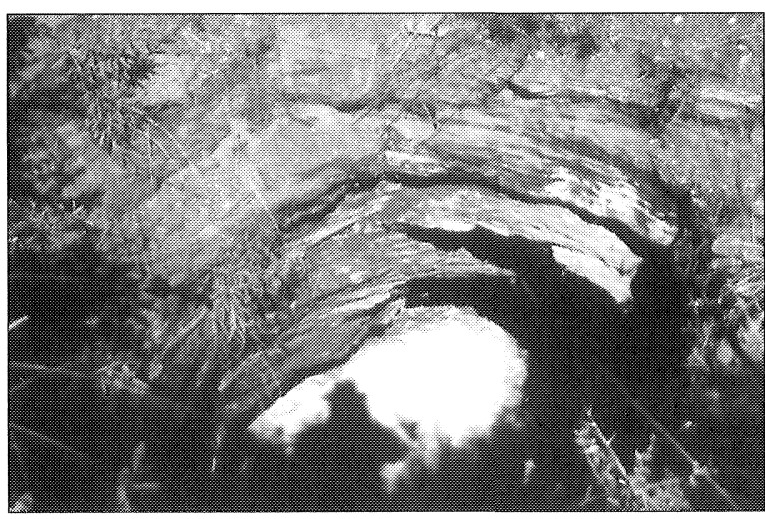

Lám. II. Pozo para descender a una mina de Kargaly. 


\begin{tabular}{|l|l|l|l|l|}
\hline \multicolumn{1}{|c|}{ Análisis } & $\mathbf{N}^{\circ}$ Invent. & $\mathbf{A g}$ & $\mathbf{S b}$ & $\mathbf{P b}$ \\
\hline PA6290 & $5128-\mathrm{e} / 5$ & 0,008 & 0,003 & 0,00 \\
\hline PA6291-1 & $5127-\mathrm{c} / 4$ & 0,005 & 0,000 & 0,00 \\
\hline PA6291-2 & $5127-\mathrm{c} / 4$ & 0,008 & 0,003 & 0,00 \\
\hline PA6291-3 & $5127-\mathrm{c} / 4$ & 0,028 & 0,002 & 0,00 \\
\hline PA6291-4 & $5127-\mathrm{c} / 4$ & 0,003 & 0,013 & 0,00 \\
\hline PA6292-1 & $5128-\mathrm{d} / 5$ & 0,032 & 0,000 & 0,00 \\
\hline PA6292-2 & $5128-\mathrm{d} / 5$ & 0,002 & 0,000 & 0,00 \\
\hline PA6292-3 & $5128-\mathrm{d} / 5$ & 0,010 & 0,000 & 0,00 \\
\hline PA6292-4 & $5128-\mathrm{d} / 5$ & 0,012 & 0,015 & 0,00 \\
\hline PA6293-1 & $5127-\mathrm{a} / 5$ & 0,000 & 0,000 & 0,00 \\
\hline PA6293-2 & $5127-\mathrm{a} / 5$ & 0,016 & 0,000 & 0,00 \\
\hline PA6293-3 & $5127-\mathrm{a} / 5$ & 0,013 & 0,012 & 0,19 \\
\hline PA6293-4 & $5127-\mathrm{a} / 5$ & 0,004 & 0,000 & 0,00 \\
\hline PA6293-5 & $5127-\mathrm{a} / 5$ & 0,000 & 0,000 & 0,00 \\
\hline PA6293-6 & $5127-\mathrm{a} / 5$ & 0,033 & 0,004 & 0,10 \\
\hline PA6293-7 & $5127-\mathrm{a} / 5$ & 0,000 & 0,010 & 0,17 \\
\hline
\end{tabular}

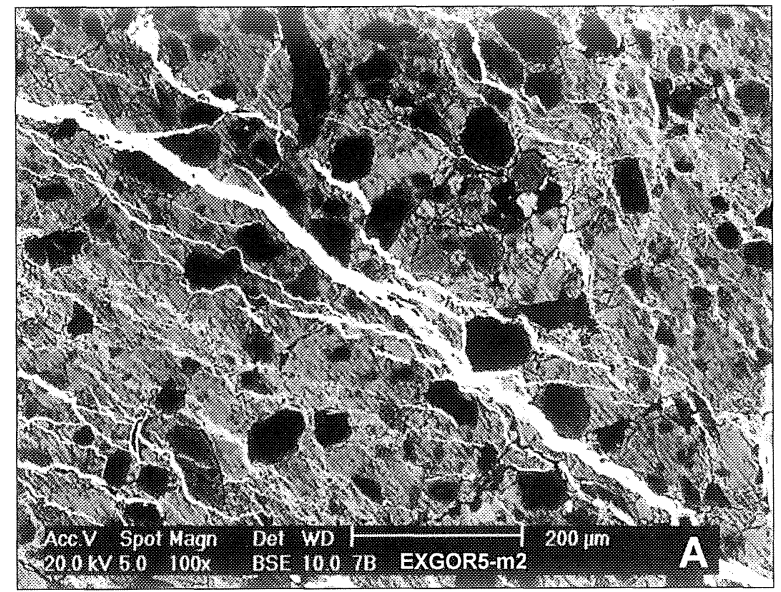

Tab. 2. Análisis de elementos traza en menas de cobre (malaquita) de Gorny (Espectrómetro de fluorescencia de rayos $\mathrm{X}, \%$ en peso respecto $100 \% \mathrm{Cu}$. No se han detectado Ni, Zn, As, Sn).

de baritina (sulfato de bario), mineral cementante frecuente en los lechos de arenisca. Sin embargo, en ocasiones, el contenido de azufre es mayor que el necesario para formar la baritina en algunas muestras (p. ej. GOR-m09), de lo que se deduce que, además de los óxidos y carbonatos de cobre, hay pequeñas cantidades de sulfato (brochantita, antlerita) (5).

Veamos con más detalle la estructura de alguno de estos minerales. La muestra EXGOR5/m02 (Lám. IIIA) es un conglomerado formado por pequeños granos de sílice (color negro) embebidos en el mineral de cobre (color gris), surcado por vetas blancas de baritina. Contiene un $30,7 \% \mathrm{CuO}$ y el resto ganga. A este mismo tipo de estructura responden las muestras EXGOR5/m1 y GOR-m13. La muestra GOR-m08 (Lám. IIIB), en cambio, es veteada, alternando distintas formas de mineral de cobre (capas de cristales poligonales), baritina (capas de color gris continuo) y arenisca (color negro). Es un mineral con poca ganga (análisis GOR-m08/4). Un tercer tipo de mena cuprífera es la GOR-m06, también estratiforme (Lám. IIIC), constituida por

(5) También podría deberse a otros sulfatos complejos con calcio, potasio y aluminio, aunque precisamente en la muestra aludida estos tres elementos son escasos, lo que refuerza la hipótesis del sulfato de cobre.
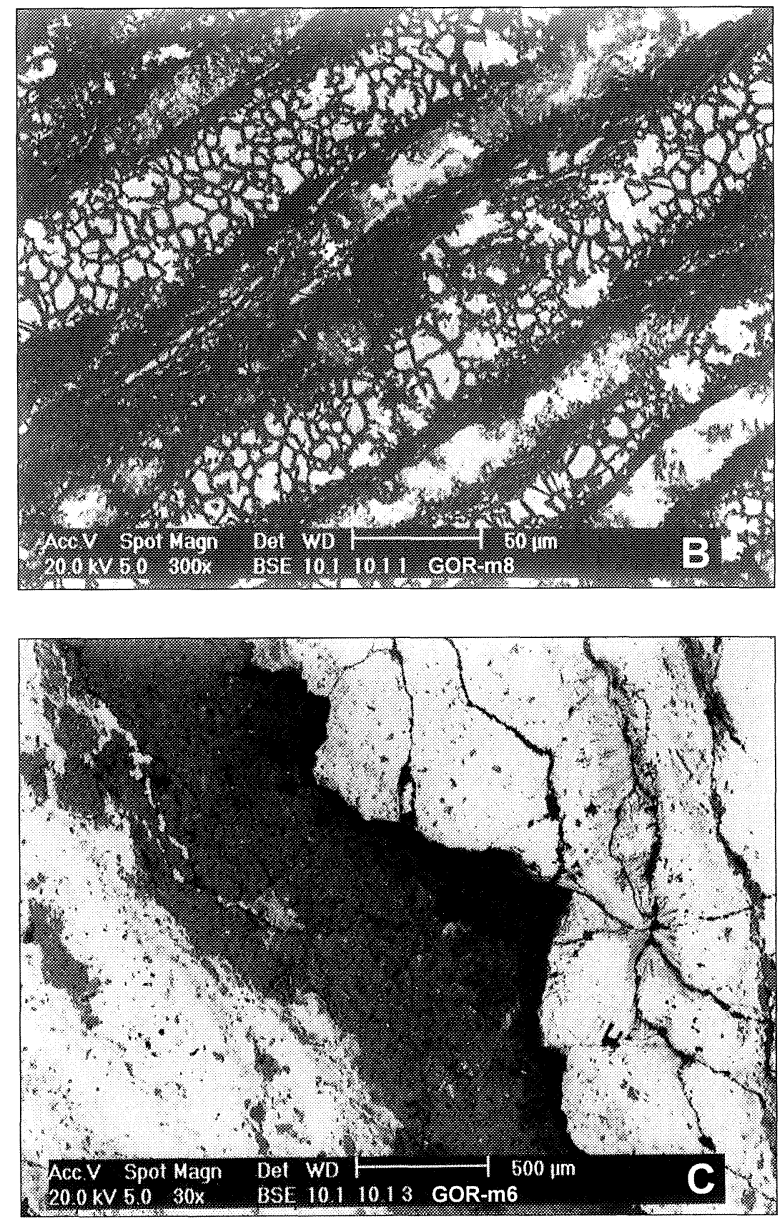

Lám. III. Imágenes obtenida en el MEB con electrones retrodispersados. A: mineral EXGOR5-m2. Las vetas blancas son de baritina; en negro los granos de sílice. B: mineral GOR-m8. Estructura veteada en la que alternan capas ricas en cobre (gris reticulado) con otras de baritina (gris continuo) y arenisca (negro). C: mineral GOR-m6. Capas ricas en cobre (gris) alternan con arenisca (negro).

T. P., 56, n.ํㄹ 1999 
capas ricas en metal (color gris claro) y capas fuertemente silicatadas (color gris oscuro).

En resumen, podríamos decir que los minerales de Gorny analizados tienen una riqueza media de cobre elevada y la ganga es predominantemente silicatada.

\begin{tabular}{|c|c|c|c|c|c|c|c|c|c|c|c|c|c|c|}
\hline Análisis & $\mathbf{N}^{\circ}$ Inventario & Fase & Región analizada & $\mathrm{FeO}$ & $\mathbf{A l}_{2} \mathbf{O}_{3}$ & $\mathrm{SiO}_{2}$ & $\mathrm{CaO}$ & MgO & $\mathrm{BaO}$ & $\mathrm{K}_{2} \mathrm{O}$ & $\mathrm{TiO}_{2}$ & $\mathrm{CrO}$ & $\mathrm{CuO}$ & So \\
\hline GOR-E01/5 & $307 / 4826-\mathrm{b} / 6$ & B-3 & General & 22,7 & 4,4 & 47.3 & 10.0 & 0 & 9.4 & 2.7 & 0 & 0 & 3,5 & 0 \\
\hline GOR-E02/1 & $326 / 5028-\mathrm{c} / 6$ & B-2 & Fayalita & 72,1 & 0 & 27,6 & 0 & 0 & 0 & 0 & 0 & 0 & 0 & 0 \\
\hline GOR-E02/2 & $326 / 5028-c / 6$ & B-2 & Relleno & 30,2 & 5,9 & 42,4 & 10,4 & 0 & 8.9 & 2.3 & 0 & 0 & 0 & 0 \\
\hline GOR-E03/4 & 4726 & B-1 & Dendritas $\mathrm{Y}$ & 3,1 & 1,5 & 35,4 & 3,7 & 0 & 10.9 & 0.73 & 0 & 0 & 44,6 & 0 \\
\hline GOR-E06/1 & $330 / 4826$ & B-1 & General & 15 & 4,3 & 53,3 & 10,6 & 0 & 7,4 & 2,4 & 0 & 0 & 7 & 0 \\
\hline GOR-E07/1 & $287 / 5126-\mathrm{d} / 3$ & B-3 & Arenisca (vid.) & 48,1 & 5 & 31,1 & 6,1 & 0 & 2,1 & 1.3 & 0 & 0 & 6.1 & 0 \\
\hline GOR-E07/2 & $287 / 5126-\mathrm{d} / 3$ & B-3 & Arenisca (gen.) & 10,5 & 7,7 & 55,8 & 12,5 & 0 & 3.6 & 2.9 & 0 & 0 & 6.9 & 0 \\
\hline GOR-E07/3 & $287 / 5126-\mathrm{d} / 3$ & B-3 & Arenisca (gen.) & 3,4 & 12,7 & 64,6 & 12,8 & 0 & 1,9 & 3 & 0 & 0 & 1,5 & $\overline{0}$ \\
\hline GOR-E08/1 & $171 / 5027$ & B-1 & General & 7,2 & 8,8 & 58 & 16,9 & 0 & 1.2 & 2.1 & 0 & 0 & 5,7 & 0 \\
\hline GOR-E09/1 & $334 / 4928$ & B-1 & Fayalita & 71,2 & 0 & 27,9 & 0,72 & 0 & 0,13 & 0 & 0 & 0 & 0 & 0 \\
\hline GOR-E09/2 & $334 / 4928$ & B-1 & Relleno & 46,3 & 4,7 & 33,6 & 9,2 & 0 & 4,3 & 1,8 & 0 & ) & 0) & ) \\
\hline GOR-E09/3 & $334 / 4928$ & B-1 & General & 60,9 & 2,2 & 27,9 & 3,7 & 0 & 1.7 & 0,71 & 0 & 0 & 0,45 & 0 \\
\hline GOR-E10/1 & $240 / 5027-d / 3$ & B-3 & General & 22,7 & 2,9 & 47,5 & 9,7 & 0 & 12.4 & 1,7 & 0 & 0 & 3 & 0 \\
\hline GOR-E10/3 & $240 / 5027-d / 3$ & B-3 & Inclusión $\mathrm{Cr}$ & 21,9 & 32,2 & 0 & 0 & 7,7 & 0 & 0 & 0 & 38,2 & 0 & 0 \\
\hline GOR-E11/1 & $320 / 5027-\mathrm{a} / 6$ & B-2 & Piroxeno & 29,6 & 5,1 & 49,2 & 4,9 & 0 & 9 & 2.2 & 0 & 0 & 0 & 0 \\
\hline GOR-E11/3 & $320 / 5027-\mathrm{a} / 6$ & B-2 & General & 21,7 & 3,7 & 43,4 & 5,6 & 0 & 8.5 & 1,7 & 0 & 0 & 15.4 & 0 \\
\hline GOR-E12/1 & $312 / 4927-a / 6$ & B-2 & General & 16,2 & 2,3 & 50,6 & 14 & 0,43 & 10,1 & 2,5 & 0 & 0 & 3,8 & $\overline{0}$ \\
\hline GOR-E13/3 & $335 / 4928$ & B-1 & Vidrio oscuro & 9,5 & 3,9 & 75,2 & 3,4 & 0 & 3,2 & 1.8 & 0 & 0 & 1,7 & 0 \\
\hline GOR-E13/4 & $335 / 4928$ & B-1 & Vidrio claro & 11,1 & 5 & 66.3 & 6,1 & 0 & 7.4 & 3 & 0 & 0 & 0 & 0 \\
\hline GOR-E13/5 & $335 / 4928$ & B-1 & General & 7,1 & 3,9 & 64,3 & 6 & 0 & 4,9 & 2,4 & 0 & 0 & 8,7 & 0 \\
\hline GOR-E14/1 & $293 / 5226$ & B-3 & Arenisca (vid.) & 4,4 & 9,8 & 69,4 & 11,6 & 0,08 & 1,7 & 2.6 & 0 & 0 & 0.11 & 0 \\
\hline GOR-E14/2 & $293 / 5226$ & B-3 & Arenisca (gen.) & 4,4 & 10.3 & 67.2 & 13,7 & 0.73 & 0,84 & 2.3 & 0 & & 0,64 & 0 \\
\hline GOR-E15/1 & $4626-b / 2$ & B-3 & Arenisca (gra.) & 84,7 & 1,2 & 6,2 & 2,9 & 0 & 0 & 0,6 & 5,4 & 0 & 0 & 0 \\
\hline GOR-E15/2 & $4626-\mathrm{b} / 2$ & B-3 & Arenisca (ag.) & 18,3 & 7,6 & 36,3 & 31,3 & 3,6 & 0 & 0.4 & 2.4 & 0 & 0 & 0 \\
\hline GOR-E15/3 & $4626-b / 2$ & B-3 & Arenisca (rell.) & 9,4 & 8,5 & 58.4 & 17,1 & 0.8 & 0 & 4.2 & 1.6 & 0 & 0 & 0 \\
\hline GOR-E15/4 & $4626-b / 2$ & B-3 & Arenisca $\mathrm{SiO} 2$ & 0 & 0 & 100 & 0 & 0 & 0 & 0 & 0) & () & 0 & 0 \\
\hline GOR-E15/5 & $4626-b / 2$ & B-3 & Arenisca (gen.) & 8,6 & 9,5 & 58,6 & 17,3 & 1,3 & 0 & 3,1 & 1.6 & 0 & 0 & 0 \\
\hline GOR-E16/4 & $4625-\mathrm{g} / 3$ & B-3 & Dendritas $\mathrm{Cu} 2 \mathrm{O}$ & 0 & 0 & 10,6 & 1,2 & 0 & 2.2 & 0 & 0 & 0 & 85.7 & 0.2 \\
\hline GOR-E16/5 & $4625-\mathrm{g} / 3$ & B-3 & Relleno & 4,1 & 0 & 50 & 7,7 & 0 & 13,3 & 1,7 & 0 & 0 & 22,8 & 0,4 \\
\hline GOR-E18/1 & $5128-c / 5(1)$ & B-3 & Dendritas $\mathrm{Cu} 2 \mathrm{O}$ & 5 & 1,4 & 20 & 2,8 & 0 & 3,0 & 0.5 & 0 & 0 & 67.2 & 0 \\
\hline GOR-E18/2 & $5128-c / 5(1)$ & B-3 & Matriz & 13,7 & 2,5 & 44,8 & 7,9 & 0 & 7.6 & 1,18 & 0 & 0 & 22,2 & 0 \\
\hline GOR-E18/5 & $5128-c / 5(1)$ & B-3 & General & 8,3 & 2,2 & 32,6 & 5,3 & 0 & 0 & 1,06 & 0 & 0 & 46,2 & 0 \\
\hline GOR-E19/1 & $5127-b / 3$ & B-3 & Fase acicular & 2,7 & 22,9 & 53,5 & 17,5 & 0 & 1,9 & 1,28 & 0 & 0 & 0 & 0 \\
\hline GOR-E19/2 & $5127-\mathrm{b} / 3$ & B-3 & Matriz & 4,8 & 13,3 & 57.6 & 14,6 & 3.2 & 3,2 & 3,11 & 0 & 0 & 0 & 0 \\
\hline GOR-E19/3 & $5127-c / 3$ & B-3 & Inclusión Cr & 38,4 & 17,8 & 0 & 0 & 3,5 & 0 & 0 & 0 & 40,2 & 0 & 0 \\
\hline GOR-E19/7 & $5127-c / 3$ & B-3 & Relleno & 10,6 & 12,9 & 53,4 & 15,2 & 2,5 & 2,5 & 2,6 & 0 & 0 & 0 & 0 \\
\hline GOR-E19/8 & $5127-c / 3$ & B-3 & General & 4,6 & 12,3 & 67.2 & 8.9 & 1,6 & 0 & 3,0 & 0 & 0 & 0 & 0 \\
\hline GOR-E20/2 & $5127-d / 4$ & B-3 & Matriz & 12,0 & 0 & 55,3 & 12,4 & 1,0 & 3,1 & 0 & 3,2 & () & 12,8 & () \\
\hline GOR-E20/3 & $5127-d / 4$ & B-3 & General & 6,5 & 0 & 37,1 & 6,2 & 0,6 & 1,1 & 2.1 & 0 & 0 & 46.2 & 0 \\
\hline GOR-E21/3 & $5127-\mathrm{b} / 5$ & B-3 & Matriz & 10,4 & 8,6 & 53.0 & 12.6 & 3,3 & 1.8 & 4,5 & 0 & 0 & 2.3 & 0 \\
\hline GOR-E21/4 & $5127-b / 5$ & B-3 & Inclusión ZrO & 2,5 & 0 & 30,1 & 0 & 0 & 0 & 0 & 0 & 0 & 0 & 0 \\
\hline GOR-E21/5 & $5127-\mathrm{b} / 5$ & B-3 & General & 6,9 & 11,2 & 70,9 & 2,6 & 0 & 1,6 & 4,0 & 0 & 0 & 2,6 & 0 \\
\hline GOR-E22/4 & $5128-\mathrm{a} / 4(2)$ & B-3 & Matriz & 15,4 & 10,9 & 61.3 & 2.7 & 2,0 & 1.6 & 2,9 & 0 & 0 & 2,3 & 0.62 \\
\hline GOR-E22/5 & $5128-\mathrm{a} / 4(2)$ & B-3 & General & 12,1 & 7,5 & 62,5 & 2,5 & 1,1 & 3,8 & 2,1 & 0 & 0 & 6,7 & 0 \\
\hline GOR-E23/4 & $5127-e / 3$ & B-3 & Matriz & 7,5 & 6,6 & 58,8 & 12,9 & 2,0 & 7.4 & 2,2 & 0 & 0 & 1,6 & 0.71 \\
\hline GOR-E23/5 & $5127-e / 3$ & B-3 & General & 8,3 & 6,6 & 54.5 & 15,8 & 1.4 & 7.0 & 2.8 & 0 & 0 & 3.0 & 0.44 \\
\hline
\end{tabular}

Tab. 3. Análisis de escorias metalúrgicas de Gorny (Microsonda MEB, \% en peso de óxidos. Sup.= Superficie). 


\begin{tabular}{|c|c|c|c|c|c|c|c|c|c|c|c|c|c|c|}
\hline Análisis & \begin{tabular}{|l}
$\mathbf{N}^{\circ}$ Inventario \\
\end{tabular} & Fase & Región analizada & $\mathrm{FeO}$ & $\mathrm{Al}_{2} \mathrm{O}_{3}$ & $\mathrm{SiO}_{2}$ & $\mathrm{CaO}$ & MgO & $\mathrm{BaO}$ & $\mathrm{K}_{2} \mathrm{O}$ & $\mathrm{TiO}_{2}$ & $\mathrm{CrO}$ & $\mathrm{CuO}$ & So \\
\hline GOR-E24/3 & $5128-\mathrm{g} / 3$ & B-3 & Inclusiones Ti & 0 & 0 & 0 & 0 & 0 & 0 & 0 & 100 & 0 & 0 & 0 \\
\hline GOR-E24/4 & $5128-\mathrm{g} / 3$ & B-3 & Matriz & 3,2 & 10,9 & 75.4 & 1,4 & 0 & 2,3 & 3.8 & 0 & 0 & 2.8 & 0 \\
\hline GOR-E24/5 & $5128-\mathrm{g} / 3$ & B-3 & General & 4,9 & 9,1 & 64,5 & 2,7 & 0 & 4,7 & 3,1 & 0 & 0 & 10,7 & 0 \\
\hline GOR-E24/5 & $5128-\mathrm{g} / 3$ & B-3 & Matriz & 10,5 & 6,1 & 60,2 & 8,3 & 0 & 9.7 & 3,3 & 0 & 0 & 1.7 & 0 \\
\hline GOR-E.25/5 & $5128-\mathrm{a} / 4(3)$ & $\mathrm{B}-3$ & Matriz & 14,4 & 4,8 & 45,2 & 5,3 & 0 & 0 & 1.5 & 0 & 0 & 28,1 & 0.39 \\
\hline GOR-E25/6 & $5128-\mathrm{a} / 4(3)$ & $\mathrm{B}-3$ & General & 14,3 & 4,1 & 48,1 & 5,0 & 0 & 0 & 1,7 & 0 & 0 & 26,1 & 0,54 \\
\hline GOR-E26/4 & $5128-\mathrm{a} / 4(1)$ & B-3 & Dendritas $\mathrm{FeO}$ & 57,1 & 2,3 & 32,3 & 1,5 & 0 & 2,1 & 2,5 & 0 & 0 & 2,1 & 0 \\
\hline GOR-E26/5 & $5128-\mathrm{a} / 4(1)$ & B-3 & Fase negra & 21.8 & 2,0 & 52,2 & 16.8 & 2,1 & 3.4 & 1.5 & 0 & 0 & 0 & 0 \\
\hline GOR-E26/6 & $5128-\mathrm{a} / 4(1)$ & B-3 & Fase gris & 17,3 & 2,3 & 52,4 & 9,3 & 1,5 & 9.6 & 2,7 & 0 & 0 & 4,7 & 0 \\
\hline GOR-E26/7 & $5128-\mathrm{a} / 4(1)$ & B-3 & General & 23,2 & 1,9 & 46,7 & 7,9 & \begin{tabular}{l|l}
1,6 \\
\end{tabular} & 7,7 & 1.8 & 0 & 0 & 9.0 & 0 \\
\hline GOR-E27/2 & $5129-\mathrm{g} / 5$ & B-3 & Cerco bolita & 70,3 & 1,4 & 14.7 & 2.2 & 0 & 2.3 & 0.94 & 0. & 0 & 8.0 & (7) \\
\hline GOR-E27/3 & $5129-\mathrm{g} / 5$ & B-3 & Fase negra & 22,3 & 2,0 & 51,5 & 15,4 & 0 & 4,2 & 1,4 & 0 & 0 & 3.0 & 0 \\
\hline GOR-E27/4 & $5129-\mathrm{g} / 5$ & B-3 & Fase gris & 16,5 & 2,9 & 51,4 & 11,1 & 0 & 8,1 & 2.0 & 0 & 0 & 7.9 & 0 \\
\hline GOR-E27/5 & $5129-\mathrm{g} / 5$ & B-3 & General & 22,8 & 3,4 & 49,6 & 7,2 & 0 & 5.8 & 2.0 & 0 & 0 & 8,9 & 0 \\
\hline GOR-E28/2 & $5127-\mathrm{e} / 4$ & B-3 & Agujas & 17,3 & 3,4 & 44,8 & \begin{tabular}{l|l}
4,9 \\
\end{tabular} & 1,4 & 12,1 & 1,4 & 0 & 0 & 14,5 & 0 \\
\hline GOR-E28/4 & $5127-\mathrm{e} / 4$ & B-3 & Matriz & 17,8 & 3,7 & 44,1 & \begin{tabular}{l|l}
3,9 \\
\end{tabular} & 0 & 11,2 & 1.1 & 0 & 0 & 18.3 & 0 \\
\hline GOR-E28/5 & $5127-\mathrm{e} / 4$ & B-3 & Aguja & 31,7 & 1,7 & 21,4 & $\begin{array}{ll}3.2 \\
\end{array}$ & 0 & 5.2 & 1,1 & 0 & 0 & 35.6 & 0 \\
\hline GOR-E28/6 & $5127-\mathrm{e} / 4$ & B-3 & General & 18,8 & 3,4 & 42,6 & \begin{tabular}{l|l}
3,9 \\
\end{tabular} & 0 & 10,7 & 1,5 & 0 & 0 & 19,1 & 0 \\
\hline GOR-E29/5 & $5128-\mathrm{a} / 2$ & B-3 & Fase negra & 31,8 & 3,6 & 54,0 & 2,4 & 0 & 3,1 & 1,9 & 0 & 0 & 0 & 0 \\
\hline \begin{tabular}{|l|} 
GOR-E29/6 \\
\end{tabular} & $5128-a / 2$ & B-3 & \begin{tabular}{|l} 
Fase gris \\
\end{tabular} & 24,5 & 3.4 & 53.5 & 6.2 & 0 & 10,4 & 1.8 & 0 & 0 & 0 & 0 \\
\hline GOR-E29/7 & $5128-\mathrm{a} / 2$ & B-3 & General & 30,6 & 4,3 & 43,0 & 4,2 & 0 & 8,5 & 1,2 & 0) & 0 & 8,0 & 0 \\
\hline GOR-E30/3 & $5128-\mathrm{b} / 5$ & B-3 & Matriz & 8,1 & 6,8 & 56,9 & 20,6 & 1,5 & 3.1 & 1.7 & 0 & 0 & 1.0 & 0 \\
\hline GOR-E30/4 & $5128-\mathrm{b} / 5$ & B-3 & General & 12,0 & 8,8 & 57,7 & 7.5 & 0.62 & 3,2 & 2,5 & 0 & 0 & 7.4 & 0 \\
\hline GOR 1-1 & & Sup. & Inclusión Ti-Fe & 37,2 & 0 & 2,6 & 2,0 & 2,4 & 0 & 0 & 55,7 & 0 & 0 & 0 \\
\hline GOR 1-2 & & Sup. & Grano sílice & 0 & 0 & 100 & 0 & 0 & 0 & 0 & 0 & 0 & 0 & 0 \\
\hline GOR 1-3 & & Sup. & Grano sílice & 0 & 0 & 100 & 0 & 0 & 0 & 0 & 0 & 0 & 0 & 0 \\
\hline GOR I-4 & & Sup. & \begin{tabular}{|l} 
Vidrio gris \\
\end{tabular} & 9,9 & 6,6 & 52,7 & 24,4 & \begin{tabular}{l|l}
3,2 \\
\end{tabular} & 0 & 3,1 & 0 & 0 & 0 & 0 \\
\hline GOR $1-5$ & & Sup. & General & 9 & 14,7 & 58,1 & 9,9 & 2.2 & 0 & 3.9 & 1.2 & 0 & 01 & 0 \\
\hline
\end{tabular}

Tab. 3 (cont.). Análisis de escorias metalúrgicas de Gorny (Microsonda MEB, \% en peso de óxidos. Sup.= Superficie)

Para determinar el contenido de elementos traza que, por su baja concentración, pasan desapercibidos en los análisis con microsonda, una serie de minerales procedentes del contexto arqueológico ha sido analizada por fluorescencia de rayos X (EDXRF), con los resultados apuntados en la tabla 2 . Como vemos, las trazas más frecuentes son las de plata, aunque tomando valores muy pequeños. Unas pocas muestras tienen antimonio, también en cantidades bajas, y otras pocas algo de plomo. No se detectan trazas de arsénico, estaño ni cinc.

\section{LAS ESCORIAS METALÚRGICAS DE GORNY}

El registro arqueológico de Gorny es pródigo en pequeños fragmentos de material escoriáceo relacionado con la metalurgia de obtención de cobre (Lám. IV). Sólo excepcionalmente se ha encontrado algún fragmento de más de $300 \mathrm{~g}$ de peso. Su aspecto externo es el de un material vítreo de fractu-

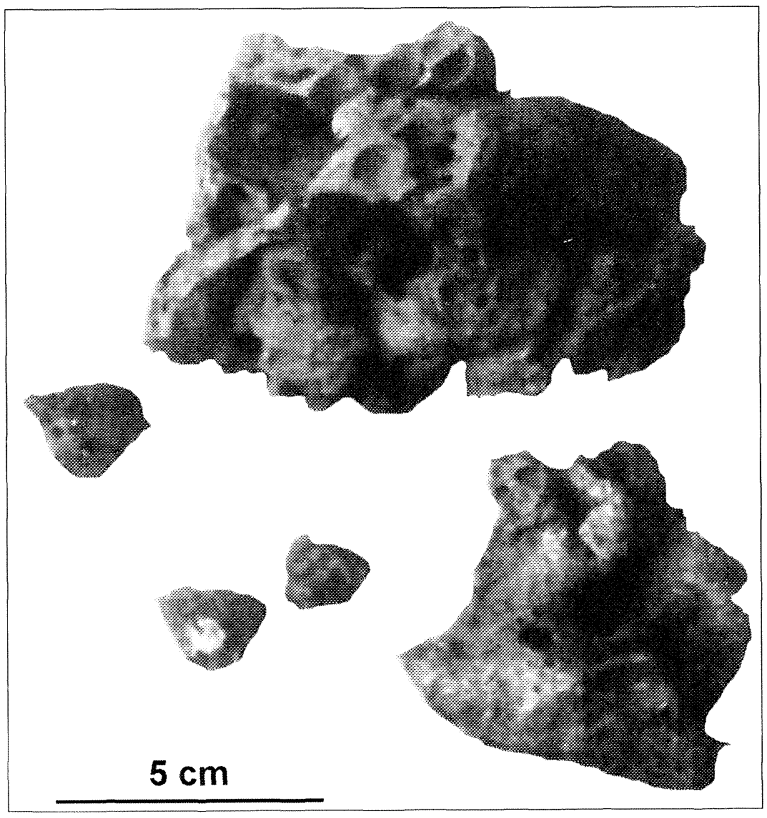

Lám. IV. Aspecto externo de las escorias de Gorny. 


\begin{tabular}{|c|c|c|c|c|c|c|c|c|c|c|c|c|}
\hline Análisis & $\mathbf{N}^{\circ}$ Inventario & Fase & Región analizada & $\mathbf{O}$ & Mg & Al & $\mathbf{S}$ & $\mathrm{Cr}$ & $\mathrm{Fe}$ & $\mathrm{Cu}$ & $\mathbf{A g}$ & $\mathbf{B a}$ \\
\hline GOR-E0I/1 & $307 / 4826-b / 6$ & B-3 & Bolita Cu & $\overline{0}$ & 0 & 0 & 0 & 0 & 0,68 & 99,3 & 0 & \\
\hline GOR-E01/2 & $307 / 4826-b / 6$ & B-3 & Corona bolita $\mathrm{Cu}$ & 0 & 0 & 0 & 17,8 & 0 & 4.73 & 77,3 & 0 & \\
\hline GOR-E01/3 & $307 / 4826-\mathrm{b} / 6$ & B-3 & Bolita Cu & 0 & 0 & 0 & 1.19 & 0 & 0,38 & 98.4 & 0 & \\
\hline GOR-E01/4 & $307 / 4826-b / 6$ & B-3 & Cristal magnetita & 27,4 & 0 & 0 & 0 & 0 & 68,8 & 3,8 & 0 & \\
\hline GOR-E03/1 & 4726 & B-1 & Bolita $\mathrm{Cu}$ & 0 & 0 & 0 & 0 & 0 & 0 & 100 & 0 & \\
\hline GOR-E03/2 & 4726 & B-1 & Corona bolita $\mathrm{Cu}$ & 7,15 & 0 & 0 & 0 & 0 & 0 & 92.8 & 0 & \\
\hline GOR-E03/3 & 4726 & B-1 & Dendritas cuprita & 10,3 & 0 & 0 & 0 & 0 & 0 & 89,7 & 0 & \\
\hline GOR-E04/1(1) & $4928-c / 6$ & B-2 & Sulfuro de cobre & 0 & 0 & 0 & 12,6 & 0 & 0 & 87.3 & 0 & \\
\hline GOR-E04/1(2) & $4928-c / 6$ & B-2 & Sulfuro de cobre & 0 & 0 & 0 & 17.8 & 0 & 0.21 & 81.4 & 0 & 0.57 \\
\hline GOR-E04/2(2) & $4928-c / 6$ & B-2 & Cu en mata & 0 & 0 & 0 & 0 & 0 & 0 & 99,7 & 0 & 0.31 \\
\hline GOR-E10/2 & $240 / 5027-d / 3$ & B-3 & Cristal de magnetita & 25,7 & 0 & 0 & 0 & 0 & 74.3 & 0 & 0 & \\
\hline GOR-E10/3 & $240 / 5027-d / 3$ & B-3 & Inclusión óxidos & 32,3 & 6,0 & 16.6 & 0 & 28,4 & 16.6 & () & 0 & \\
\hline GOR-E11/2 & $320 / 5027-a / 6$ & B-2 & Cristal magnetita & 26,5 & 0 & 0 & 0 & 1,27 & 69,8 & 2,4 & 0 & \\
\hline GOR-E12/2 & $312 / 4927-a / 6$ & B-2 & Bolita $\mathrm{Cu}$ & 0 & 0 & 0 & 0 & 0 & 0 & 100 & 0 & \\
\hline GOR-E12/3 & $312 / 4927-\mathrm{a} / 6$ & B-2 & Corona bolita $\mathrm{Cu}$ & 0 & 0 & 0 & 18.4 & 0 & 2.08 & 79.4 & 0 & \\
\hline GOR-E12/4 & $312 / 4927-a / 6$ & B-2 & Sulfuro en bolita $\mathrm{Cu}$ & 0 & 0 & 0 & 8,49 & 0 & 0,06 & 91,4 & 0 & \\
\hline GOR-E13/1 & $335 / 4928$ & B-1 & Corona bolita $\mathrm{Cu}$ & 9,17 & 0 & 0 & 0 & 0 & 0 & 93,8 & 0 & \\
\hline GOR-E13/1b & $335 / 4928$ & B-1 & Bolita Cu & 0 & 0 & 0 & 0 & 0 & 0 & 100 & 0 & \\
\hline GOR-E13/2 & $335 / 4928$ & B-1 & Bolita Cu2S & 0 & 0 & 0 & 17,8 & 0 & 0 & 82,1 & 0 & \\
\hline GOR-E16/1 & $4625-\mathrm{g} / 3$ & B-3 & Bolita $\mathrm{Cu}$ & 0 & 0 & 0 & 0 & 0 & 0 & 100 & 0 & \\
\hline GOR-E16/2 & $4625-\mathrm{g} / 3$ & B-3 & Corona bolita $\mathrm{Cu}$ & 11,0 & 0 & 0 & 0 & 0 & 0 & 89,0 & 0 & \\
\hline GOR-E16/3 & $4625-\mathrm{g} / 3$ & B-3 & Inclusión bolita $\mathrm{Cu}$ & 10,8 & 0 & 0 & 0 & 0 & 0 & 89,2 & 0 & \\
\hline GOR-E17/1 & $4725-\mathrm{g} / 3$ & B-3 & Bolita $\mathrm{Cu}$ en $\mathrm{Cu} 2 \mathrm{~S}$ & 0 & 0 & 0 & 0 & 0 & 0 & 100 & 0 & \\
\hline GOR-E17/2 & $4725-\mathrm{g} / 3$ & B-3 & Sulfuro de $\mathrm{Cu}$ & 0 & 0 & 0 & 17,0 & 0 & 0 & 83.0 & 0 & \\
\hline GOR-E18/3 & $5128-c / 5(1)$ & B-3 & Bolita Cu2O & 10,6 & 0 & 0 & 0 & 0 & 0 & 89,4 & 0 & \\
\hline GOR-E18/4 & $5128-c / 5(1)$ & B-3 & Inclusión $\mathrm{Cu}-\mathrm{Ag}$ & 0 & 0 & 0 & 0 & 0 & 0 & 67.8 & 32,2 & \\
\hline GOR-E19/4 & $5127-\mathrm{c} / 3$ & B-3 & Inclusión Fe & 0 & 0 & 0 & 0 & 0 & 100 & 0 & 0 & \\
\hline GOR-E19/5 & $5127-c / 3$ & B-3 & Bolita $\mathrm{Cu}$ & 0 & 0 & 0 & 0 & 0 & 0 & 100 & 0 & \\
\hline GOR-E19/6 & $5127-c / 3$ & B-3 & Inclusión Fe & 0 & 0 & 0 & 0 & 0 & 100 & 0 & 0 & \\
\hline GOR-E20/1 & $5127-d / 4$ & B-3 & Dendritas $\mathrm{Cu} 2 \mathrm{O}$ & 11,1 & 0 & 0 & 0 & 0 & 0 & 88.9 & 0 & \\
\hline GOR-E21/1 & $5127-b / 5$ & B-3 & Bolita $\mathrm{Cu} 2 \mathrm{O}$ & 10,7 & 0 & 0 & 0 & () & 0 & 89,3 & 0 & \\
\hline GOR-E21/2 & $5127-b / 5$ & B-3 & Bolita Cu & 0 & 0 & 0 & 0 & 0 & 0 & 100 & 0 & \\
\hline GOR-E22/1 & $5128-a / 4(2)$ & B-3 & Bolita Cu * & 0 & 0 & 0 & 0 & 0 & 0 & 100 & 0 & \\
\hline GOR-E22/2 & $5128-\mathrm{a} / 4(2)$ & B-3 & Cerco bolita $\mathrm{Cu}$ & 11,0 & 0 & 0 & 0 & 0 & () & 89,0 & 0 & \\
\hline GOR-E22/3 & $5128-\mathrm{a} / 4(2)$ & B-3 & Cerco bolita $\mathrm{Cu}$ & 0 & 0 & 0 & 15,8 & 0 & 0 & 84,2 & 0 & \\
\hline GOR-E23/1 & $5127-e / 3$ & B-3 & Bolita $\mathrm{Cu}$ & 0 & 0 & 0 & 0 & 0 & 0 & 100 & 0 & 0 \\
\hline GOR-E23/2 & $5127-\mathrm{e} / 3$ & B-3 & Cerco bolita $\mathrm{Cu}$ & 10,8 & 0 & 0 & 0 & 0 & 0 & 89,2 & 0 & \\
\hline GOR-E23/3 & $5127-e / 3$ & B-3 & Cerco bolita $\mathrm{Cu}$ & 0 & 0 & 0 & \begin{tabular}{l|}
30,2 \\
\end{tabular} & 0 & 0 & 69,8 & 0 & \\
\hline GOR-E24/1 & $5128-\mathrm{g} / 3$ & B-3 & Bolita $\mathrm{Cu}$ & 0 & 0 & 0 & 0 & 0 & 0 & 100 & 0 & \\
\hline GOR-E24/2 & $5128-\mathrm{g} / 3$ & B-3 & Bolita $\mathrm{Cu} 2 \mathrm{O}$ & 10,5 & 0 & 0 & 0 & 0 & 0 & 89,5 & 0 & 0 \\
\hline GOR-E25/1 & $5128-\mathrm{a} / 4(3)$ & B-3 & Inclusión bolita $\mathrm{Cu}$ & 11,1 & 0 & 0 & 0 & 0 & 0 & 88,9 & 0 & \\
\hline GOR-E25/2 & $5128-a / 4(3)$ & B-3 & Inclusión bolita $\mathrm{Cu}$ & 0 & 0 & 0 & 20.8 & 0 & 0 & 79.1 & 0 & \\
\hline GOR-E25/3 & $5128-\mathrm{a} / 4(3)$ & B-3 & Bolita $\mathrm{Cu}$ & 0 & 0 & 0 & 0 & 0 & 2,5 & 97,4 & 0 & \\
\hline GOR-E25/4 & $5128-\mathrm{a} / 4(3)$ & B-3 & Bolita Cu2S & 0 & 0 & 0 & 12.3 & 0 & 6.9 & 80.9 & 0 & \\
\hline GOR-E26/1 & $5128-a / 4(1)$ & B-3 & Bolita $\mathrm{Cu}$ & 0 & 0 & 0 & 2,5 & 0 & 0 & 97.5 & 0 & \\
\hline GOR-E26/2 & $5128-\mathrm{a} / 4(1)$ & B-3 & Cerco bolita $\mathrm{Cu}$ & 0 & 0 & 0 & 19,0 & 0 & 0 & 81,0 & 0 & \\
\hline GOR-E26/3 & $5128-a / 4(1)$ & B-3 & Cristal magnetita & 25,0 & 0 & 0 & 0 & 0 & 75.0 & 0 & 0 & \\
\hline GOR-E27/1 & $5129-g / 5$ & B-3 & Bolita Cu & 0 & 0 & 0 & 0 & o & 0.8 & 99.2 & 0 & \\
\hline
\end{tabular}

Tab. 4. Análisis de escorias metalúrgicas de Gorny (Microsonda MEB, \% en peso de elementos). 


\begin{tabular}{|c|c|c|c|c|c|c|c|c|c|c|c|c|}
\hline Análisis & $\mathbf{N}^{\circ}$ Inventario & Fase & Región analizada & $\mathbf{O}$ & $\mathrm{Mg}$ & $\overline{A l}$ & $\mathbf{S}$ & $\mathrm{Cr}$ & $\mathrm{Fe}$ & $\mathbf{C u}$ & $\overline{\mathrm{Ag}}$ & $\mathbf{B a}$ \\
\hline GOR-E28/1 & $5127-\mathrm{e} / 4$ & B-3 & Bolita Cu2O & 10,8 & 0 & 0 & 0 & 0 & 0 & 89.2 & 0 & 0 \\
\hline GOR-E28/3 & $5127-\mathrm{e} / 4$ & B-3 & Bolita Cu & 0 & 0 & 0 & 0 & 0 & 2,0 & 97,9 & 0 & 0 \\
\hline GOR-E29/1 & $5128-\mathrm{a} / 2$ & B-3 & Bolita $\mathrm{Cu}$ & 0 & 0 & 0 & 0 & 0 & 0 & 100 & 0 & 0 \\
\hline \begin{tabular}{|l} 
GOR-E29/2 \\
\end{tabular} & $5128-a / 2$ & B-3 & Cerco bolita $\mathrm{Cu}$ & 10,9 & 0 & 0 & 0 & 0 & 0 & 89.1 & 0 & $\overline{0}$ \\
\hline GOR-E29/3 & $5128-a / 2$ & B-3 & Cerco bolita $\mathrm{Cu}$ & 0 & 0 & 0 & 21,3 & 0 & 0 & 78,7 & 0 & 0 \\
\hline GOR-E29/4 & $5128-\mathrm{a} / 2$ & $\mathrm{~B}-3$ & Cristal magnetita & 24,0 & 0 & 0 & 0 & 0 & 76,0 & 0 & 0 & 0 \\
\hline GOR-E30/1 & $5128-\mathrm{b} / 5$ & B-3 & Bolita Cu2S & 0 & 0 & 0 & 19.5 & 0 & 0 & 20.5 & 0 & 0 \\
\hline GOR-E30/2 & $5128-\mathrm{b} / 5$ & B-3 & Bolita baritina & 27,0 & 0 & 0 & 13,4 & 0 & 0 & 0 & 0 & 59,6 \\
\hline
\end{tabular}

Tab. 4 (cont.). Análisis de escorias metalúrgicas de Gorny (Microsonda MEB, $\%$ en peso de elementos).

ra concoidea, de superficies bulbosas como consecuencia de haber estado fundido o, al menos, en estado pastoso. Suelen ser porosas en su interior (salvo excepciones) y el color es variable: desde el rojo de la cuprita al negro brillante. A menudo se perciben a simple vista pequeñas inclusiones esféricas de cobre metálico o de sulfuro de cobre.

No hay escoriales en las inmediaciones del yacimiento ni en los alrededores, a pesar de las minuciosas prospecciones llevadas a cabo sobre el terreno en un radio de varios kilómetros en torno al sitio de Gorny, hecho llamativo que contrasta con la opinión fuertemente arraigada entre los colegas rusos de que la producción de cobre en Kargaly durante la Edad del Bronce debió ascender a varios cientos de miles de toneladas (Chernykh, 1998: 72). Esta circunstancia junto con la naturaleza de las escorias nos hizo pronto pensar que nos hallábamos ante un peculiar gran centro minero-metalúrgico con rasgos tecnológicos muy distintos a los conocidos hasta ahora, como por ejemplo los casos de Feinan (Jordania) (Hauptmann, 1989) y WadiArabah (Israel) (Rothenberg, 1985).

Durante el desarrollo del proyecto se han seleccionado y analizado treinta muestras de escorias con los resultados expuestos en las tablas 3 y 4 , que comentaremos a continuación. Los análisis generales, representativos de la composición global de la muestra, indican que son escorias con altos contenidos de sílice, del orden del 50\% o más, salvo alguna excepción. La fracción de óxido de hierro es, por el contrario, baja, frecuentemente menor que el $10 \% \mathrm{FeO}$; unas pocas se sitúan entre el $20 \%$ y el $30 \%$, y tan sólo una alcanza el $60 \%$ FeO (GORE09/3). El contenido de calcio es variable, aunque son frecuentes los valores alrededor del $10 \% \mathrm{CaO}$. Otros acompañantes habituales son aluminio, bario, potasio y, más raramente, magnesio.

Conservan mucho cobre, bien como bolitas metálicas con diámetros que van desde unas cuan- tas micras a dos o tres milímetros (Lám. V), o como minerales sin reducir. Las pérdidas de cobre en la escoria son también irregulares; algunas, como la muestra GOR-E09/3, apenas arrastra un $0,45 \% \mathrm{CuO}$; otras como la GOR-E19/8 y la GORE20/3 mantienen atrapado un $46 \% \mathrm{CuO}$. La figura 2 representa gráficamente la retención de cobre en la escoria.

Las posiciones de las escorias en el diagrama ternario $\mathrm{CaO}-\mathrm{FeO}-\mathrm{SiO}_{2}$ de equilibrio de fases, calculadas tras eliminar el cobre, es decir, suponiendo que todo el cobre ha sido extraído, se distribuyen según el gráfico de la figura 3 en el que se observan tres agrupamientos: uno por encima de la región de la cristobalita, con temperaturas de fusión superiores a los $1.600^{\circ} \mathrm{C}$; otro en la región de la tridimita cuyas temperaturas están entre $1.200^{\circ}$ y algo más de $1.400^{\circ} \mathrm{C}$, y un tercero, formado por una sola muestra, cae en la región del olivino (fayalita), que funde entre $1.100^{\circ}$ y $1.200^{\circ} \mathrm{C}$.

Aun sin entrar en estudios de detalle sobre la estructura de fases de las escorias de Gorny, es evidente que constituyen un conjunto de materiales

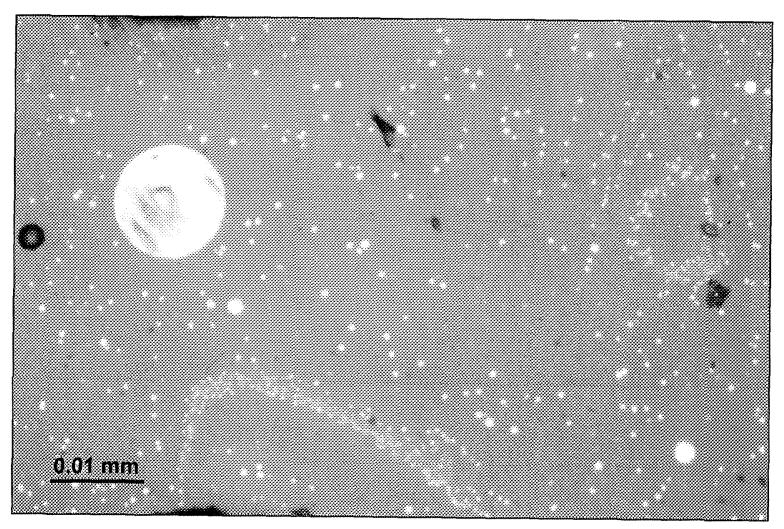

Lám.V. Imagen obtenida con el MO de una escoria característica de Gorny. Obsérvese la estructura amorfa conteniendo bolitas de cobre (blanco) de diferentes tamaños. 


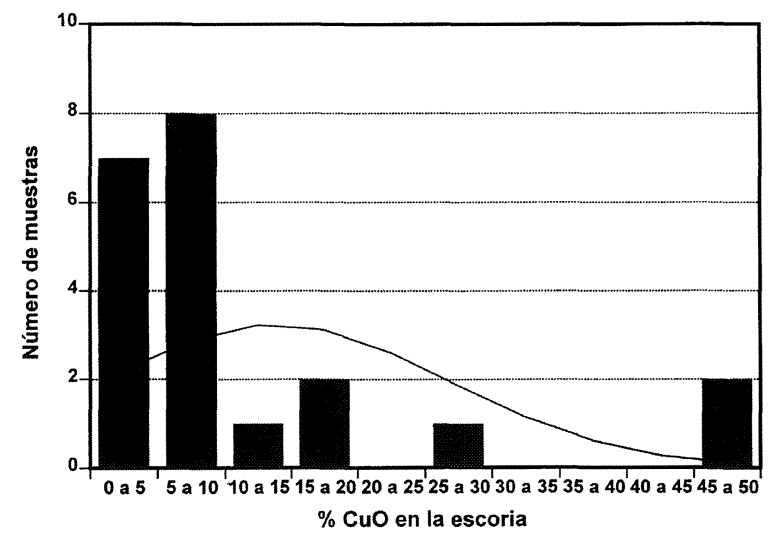

Fig. 2. Histograma representando el porcentaje de óxido de cobre retenido en las escorias de Gorny. La mayor parte de las muestras retienen menos del $10 \%$ y las restantes, especialmente las de mayor retención, son más bien porciones de óxido cuproso sin reducir.

muy heterogéneo, alejado de la composición canónica de una escoria de bajo punto de fusión (excepto el ejemplar del tercer grupo antes mencionado, que parece una excepción). Dejando a un lado que el diagrama ternario empleado para la representación no se adapta bien a estos materiales por las razones que más adelante se irán viendo, hecho que ya había sido puesto en evidencia por otros autores (Hauptmann et alii, 1996: 9, Fig. 4), la primera impresión que se recoge es que son necesarias temperaturas muy elevadas para extraer el cobre del mineral. Sin embargo, tales temperaturas son impensables en los hornos prehistóricos y, por tanto, la comprensión del proceso de formación de estas escorias ha de hacerse por otras vías.

Los estudios microscópicos permiten apreciar varios tipos de estructuras en las cuales reside el quid de la cuestión. Tenemos, por un lado, escorias con abundante sílice libre que no ha reaccionado con el resto de los componentes del material. Un ejemplo típico es la muestra GOR-E30, cuya estructura general se aprecia en la láminaVIA. Abundantes granos de sílice (de color gris oscuro) tapizan el campo observado. Sus perfiles abruptos y limpios son la mejor evidencia de que están intactos $y$, por tanto, no han intervenido en ninguna reacción química durante la formación de la escoria. Esta sílice puede provenir de la carga en el horno de minerales como el representado en la lámina IIIA o de fragmentos de roca encajante triturados inadvertidamente junto con la mena metalífera. El resultado es una especie de conglomerado unido por una matriz amorfa que contiene piroxeno y akermani- ta, principalmente, formados por la reacción de una parte del silicio con el calcio, aluminio, hierro, bario, magnesio y potasio presentes (análisis GORE30/3). La pérdida de cobre es relativamente baja (un $1 \%$ en la matriz y un 7,4\% en el análisis global), la mayor parte en forma de bolitas metálicas (véase Lám. VIA), lo cual indica que se consiguió reducir con éxito el mineral de cobre. El exceso de sílice libre falsea la analítica, pues si en lugar de representar en el diagrama ternario la composición general equivalente $\left(71,9 \% \mathrm{SiO}_{2}, 15 \% \mathrm{CaO}, 13 \% \mathrm{FeO}\right)$, usáramos la de la matriz vítrea (la verdadera escoria), $64,5 \% \mathrm{SiO}_{2}, 27,3 \% \mathrm{CaO}, 8,2 \% \mathrm{FeO}$, la temperatura de fusión sería ahora de unos $300^{\circ} \mathrm{C}$ menos $\mathrm{y}$, aunque sigue siendo elevada, se aproxima más a cotas reales alcanzables en el horno. Esta es una de las razones por las cuales el diagrama de fases no es fiable para representar escorias inmaduras como las de Gorny, cuando la proporción de sílice es demasiado alta, maýor del $60 \%$.

Cuando la composición de la escoria es del orden de $20 \% \mathrm{FeO}, 40 \% \mathrm{SiO}_{2}, 20 \% \mathrm{CuO}$ y cantidades menores de calcio y aluminio, se forman finas agujas de material piroxénico (Lám. VIB). Es el caso de las escorias GOR-E11 y GOR-E28.

En el extremo opuesto tendríamos las escorias muy ricas en cobre, como la GOR-E20, con un $46,2 \% \mathrm{CuO}$ residual. Es más propiamente un mineral de cobre fundido que una escoria, como demuestra su estudio microscópico (Lám.VIC). El campo está dominado por formaciones dendríticas de óxi-

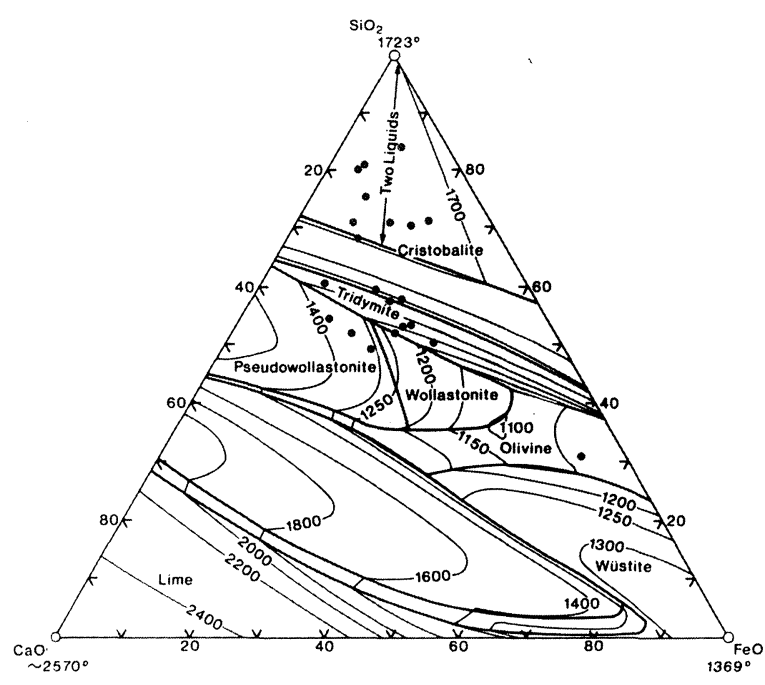

Fig. 3. Diagrama de equilibrio de fases de las escorias arqueológicas de Gorny. Nótese su distribución en tres grupos. 

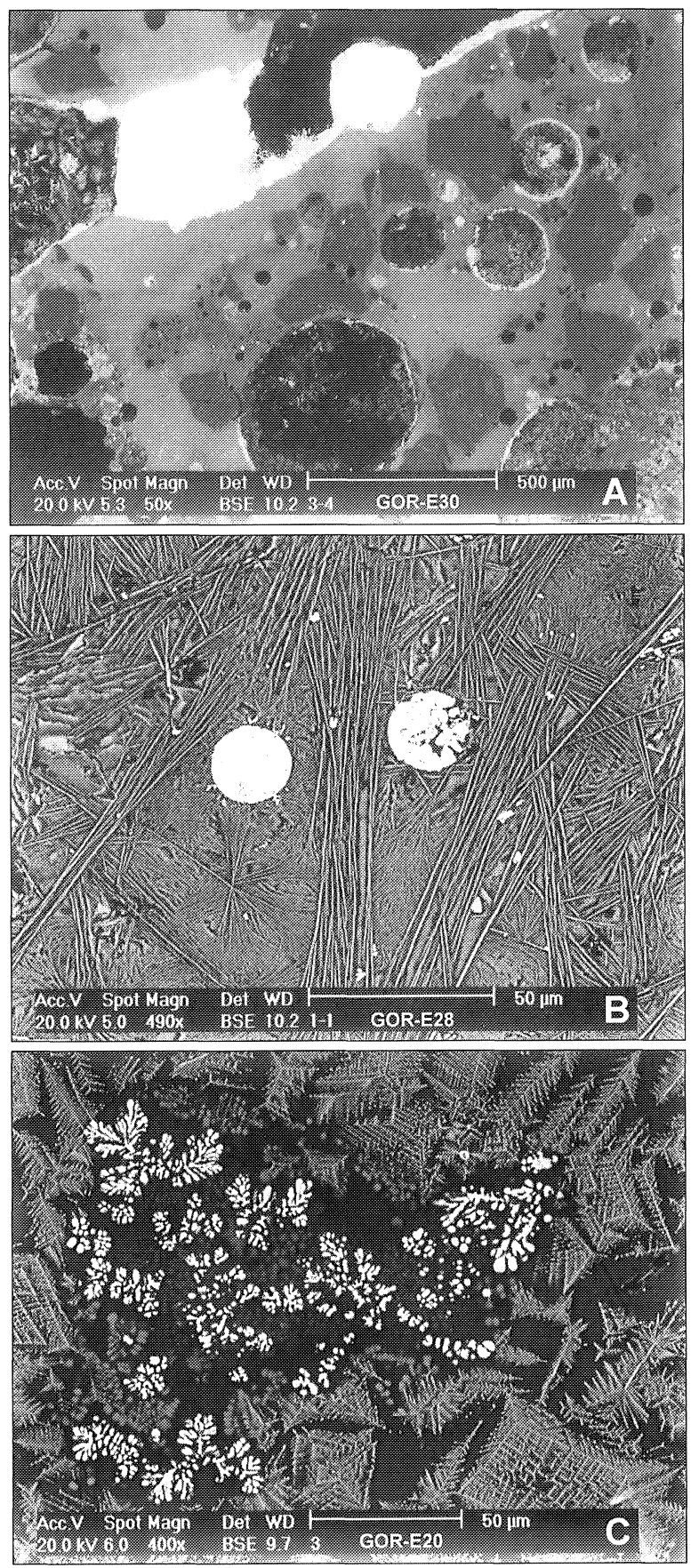

Lám.VI. Imágenes obtenidas con el MEB con electrones retrodispersados. A: escoria GOR-E30. En blanco, cobre retenido. Se aprecia sílice libre (granos de color gris oscuro y perfiles abruptos) en una matriz de vidrio silícico (gris). Las formaciones circulares son vacuolas. B: escoria GORE28. El campo está dominado por formaciones de finas agujas de piroxeno. En el centro de la imagen se aprecian dos esferas de cobre. C: escoria GOR-E20. Formaciones dendríticas de cuprita con dos morfologías diferentes: racimos y esqueletos lineales ramificados. do cuproso (análisis GOR-E20/1) en una matriz piroxénica (análisis GOR-E20/2) en la que también hay mineral en disolución, probablemente en forma de delafosita. La buena disposición de las dendritas sugiere que el material estuvo a una temperatura generosamente por encima de la de fusión de la cuprita y se enfrió con cierta lentitud para dar tiempo al crecimiento ordenado de las dendritas pequeñas. Es interesante hacer notar que esta escoria no contiene bolitas de metal, lo cual significa que el ambiente en el que se formó no alcanzó las condiciones reductoras necesarias.

Sólo dos muestras tienen fayalita cristalizada, la GOR-E2 y la GOR-E9, debido a su alto contenido en hierro. En ambos ejemplares los cristales son de tamaños irregulares y poco ordenados, con estructuras nacientes (Lám.VII). No se aprecian fenómenos de re-disolución, lo que podría interpretarse como que el proceso de formación fue rápido o, lo que es lo mismo, que el tiempo de funcionamiento del horno, una vez alcanzada la temperatura de trabajo, fue relativamente breve. La estructura general de estas escorias está constituida por cristales de fayalita en una matriz de relleno formada por un vidrio ferrosilicatado conteniendo calcio y aluminio (análisis GOR-E2/2 y GOR-E9/2). Una de las características de estas escorias es, como era de esperar, su baja retención de cobre $(0,45 \% \mathrm{CuO}$ en GOR-E9/3), ya que al encontrarse fundidas entre $1.150^{\circ}$ y $1.200^{\circ} \mathrm{C}$, el metal formado se separa como gotas líquidas por su diferencia de densidades.

Las inclusiones más numerosas y habituales de las escorias de Gorny son las de cobre metálico y de

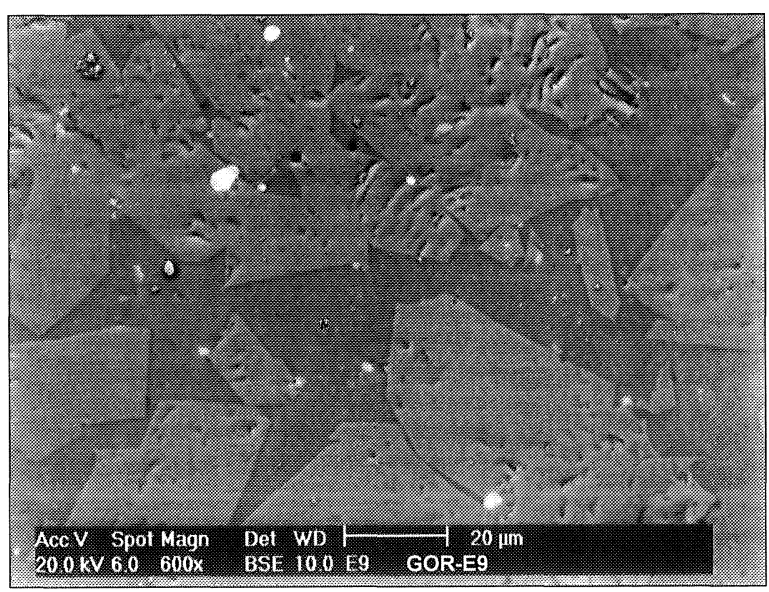

Lám. VII. Imagen obtenida en el MEB con electrones retrodispersados de la escoria GOR-E9. Cristales tabulares de fayalita. Se aprecian numerosas bolitas de cobre metálico (blanco). 
sulfuro de cobre $\left(\mathrm{Cu}_{2} \mathrm{~S}\right)$, generalmente en forma de esferas de tamaños variables. Las estudiaremos con detalle en el próximo epígrafe. Otras, menos frecuentes, son los nodulillos microscópicos de baritina, óxido de bario y de óxido de titanio. Un último grupo lo forman inclusiones raras con cromo (GOR-E10/3 y GOR-E19/3) y con plata-cobre (GOR-E18/4). Todas ellas se justifican plenamente atendiendo a la composición de los minerales de Gorny (véanse las Tabs. 1 y 2) (6).

Otro componente habitual de estas escorias es la magnetita. Suele aparecer como cristales aislados o como familias de cristales. Raramente en forma dendrítica, como en la muestra GOR-E26 (Lám. VIII). Esta imagen es muy ilustrativa ya que evidencia que se alcanzaron temperaturas muy altas (7), superiores a los $1.300^{\circ} \mathrm{C}$, con lo que el grupo de escorias de la figura 3 que se encuentra entre las isotermas de $1.200^{\circ} \mathrm{y} 1.400^{\circ} \mathrm{C}$ podría estar configu-rando una situación real. Confirmación de este supuesto la proporcionan los fragmentos de arenisca vidriada superficialmente por efecto térmico, sin duda por formar parte de las estructuras en las que se fundió mineral (véase laTab. 3). Por otro lado, la presencia de magnetita es una indicación fiel de que había períodos de ambiente oxidante en el horno.

Una serie de muestras de escoria ha sido analizada en el espectrómetro de fluorescencia de rayos $\mathrm{X}$, comprobando así que contienen también impurezas de plata, antimonio y plomo en el orden de magnitud de las decenas de partes por millón, como ocurre con los minerales (véase la Tab. 2).

En general la composición de las escorias se corresponde bastante bien con la de los minerales, teniendo en cuenta la poca homogeneidad compositiva de ambos conjuntos y la selección al azar las muestras. Siendo estrictos, las diferencias entre los valores medios de $\mathrm{K}$, Ca y Fe en las escorias son significativas (8), lo cual podría interpretarse como

(6) El cromo no ha sido detectado en los minerales, pero ello se debe a su presencia excepcional que lo hace imposible de detectar con los medios analíticos empleados.

(7) El óxido ferroso funde a $1.377^{\circ} \mathrm{C}$, aunque la formación de wüstita dendrítica en una escoria quizá se inicie a una temperatura algo más baja. La magnetita funde a $1.597^{\circ} \mathrm{C}$. No podemos pensar que en los hornos de Gorny se alcanzara la temperatura de fundición de la magnetita, por lo que la imagen de las dendritas de la lámina VI hay que interpretarla como consecuencia de la reducción de la magnetita a wüstita, a una temperatura superior a los $1.300^{\circ} \mathrm{C}$, situación en la cual el óxido ferroso fundiría y formaría las dendritas que parten de los vértices (en realidad aristas) de los cristales de sección poligonal.

(8) Según se desprende de la aplicación del test estadístico del análisis de la varianza a las composiciones medias, una vez eliminado el efecto del cobre presente.

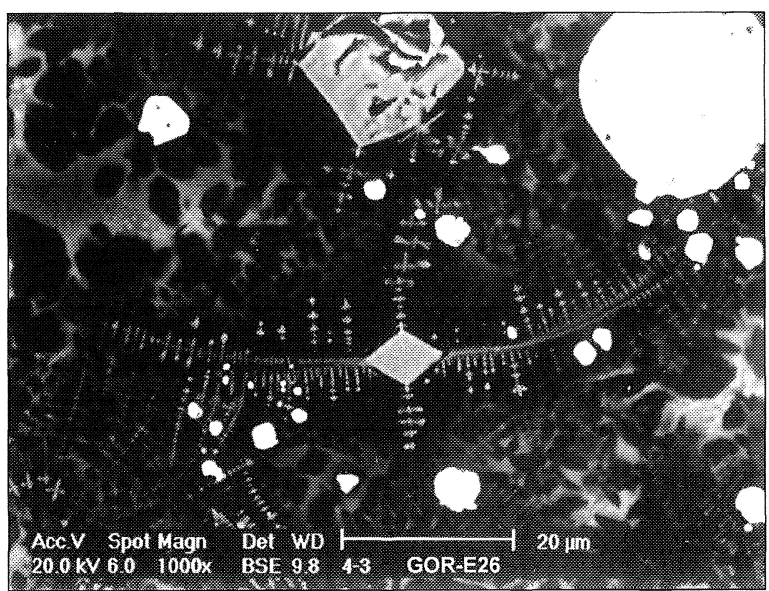

Lám. VIII. Imagen obtenida en el MEB con electrones retrodispersados de la escoria GOR-E26. Obsérvese la formación de finas dendritas de óxido de hierro que parten de las aristas de los cristales de magnetita. La escoria retiene en esta zona numerosas bolitas de cobre de distintos tamaños.

una adición intencionada de un fundente ferrocalizo a la carga del horno. Pero hay varias consideraciones que invitan a no tomar en cuenta al pie de la letra los resultados estadísticos. En primer lugar, este supuesto fundente no facilitaría substancialmente el proceso general de escorificación, como demuestran los análisis estructurales de las escorias. En segundo lugar, ya hemos dicho al hablar de los minerales que existe en algunas mineralizaciones una capa de conglomerados calizos algo ferruginosos que contienen también malaquita: la explotación de minerales de dicha capa puede justificar las variaciones estadísticas observadas. Finalmente, la diferencia de potasio, elemento que se encuentra en la arenisca, confirma que se explotaron mineralizaciones con distintas composiciones de caja, lo cual afecta también al calcio y al hierro, y no debe sorprender si recordamos que los materiales de las tablas 3 y 4 corresponden a todas las fases de ocupación del yacimiento de Gorny.

Así, pues, estas escorias son consecuencia de un proceso de obtención de cobre directamente de los minerales, sin que los antiguos metalúrgicos de esta localidad de la estepa rusa emplearan ningún procedimiento para facilitar la extracción por procedimientos de escorificación añadiendo fundentes. Las escorias reflejan la composición química de los minerales que, en este caso, son poco autofundentes por su bajo contenido en hierro. A pesar de todo, el rendimiento medio teórico de la operación es del orden del 73,6\%, es decir, de cada 100 $\mathrm{kg}$ de mineral con una composición media del 
$43,6 \% \mathrm{CuO}(9)$ (equivalente a $34,9 \mathrm{~kg}$ de cobre elemental) se reduciría el $32,1 \% \mathrm{CuO}$ (equivalente a $25,7 \mathrm{~kg}$ de cobre metálico) y quedarían retenidos en la escoria los 9,2 kg de cobre restantes, como pequeñas bolitas de metal y como óxidos no reduci-dos (10). El residuo sólido, una vez separado el cobre, sería de unos $35-40 \mathrm{~kg}$ y el resto de materiales se habría volatilizado en los humos (11).

El paralelo más cercano a las escorias de Gorny lo encontramos en los subproductos de fundición calcolíticos de Wadi Fidan 4, Jordania, donde se explotaban minerales de cobre de las areniscas de Feinan (Hauptmann et alii, 1996: 4). A pesar de la diferencia temporal (el Calcolítico de Feinan discurre entre el 4500-3100 a.C., mientras que Gorny se ha fechado entre 1690 y 1410 AC según Chernyj et alii, 1999: 98) en ambos casos nos enfrentamos a procesos sencillos de reducción directa de minerales, sin empleo de fundentes. Hay diferencias de procedimiento, pues los metalúrgicos prehistóricos jordanos utilizaban crisoles de entre 11 y $13 \mathrm{~cm}$ de diámetro para fundir el mineral, dotados de mango para verter su contenido, lo cual significa, como bien deducen los mencionados autores, que intentaban conseguir metal líquido u óxido cuproso fundido para separarlo más fácilmente de la ganga. En Gorny no conocemos estructuras de horno metalúrgico ni tampoco crisoles excepto los usados habitualmente para fundir el metal.

En Norsun-Tepe, en el alto Éufrates, se beneficiaron también minerales de cobre encajados en arenisca (aunque sin bario) desde mediados del IV milenio a.C. Los estudios y experimentos de Zwicker (1980) demostraron que se podía extraer con cierta facilidad hasta un $25 \%$ en peso del cobre de la carga (una cifra muy similar a la que hemos calculado para Gorny), sin rebasar temperaturas del orden de los $1.200^{\circ} \mathrm{C}$. En los experimentos no se usaron fundentes y la proporción mineral/carbón era de 1:1 en peso.

(9) Dato obtenido promediando los análisis generales de minerales de la tabla 1 .

(10) Véase más adelante la crítica realizada a estos cálculos, basada en los experimentos de fundición realizados durante la campaña de 1998.

(11) No olvidemos que estamos trazando un modelo teórico basado en los datos aportados por los materiales recogidos y analizados. Su bondad depende de la representatividad que queramos otorgar a dichos datos. En cualquier caso, sirve para hacernos una idea, aunque sea aproximada, del rendimiento y volumen de cobre obtenido. No obstante, véase más adelante la crítica a este modelo.

\section{EL COBRE DE GORNY}

Las excavaciones realizadas hasta el momento en el sitio han puesto al descubierto una vivienda de la Fase B-1 dedicada a actividades metalúrgicas (Fig. 4), constituida por un espacio presumiblemente cubierto, habitable, dispuesto alrededor de un hogar, que comunicaba a través de un ligero estrangulamiento con otro espacio descubierto, a manera de patio, donde al parecer se realizaban las tareas pirometalúrgicas. En la parte central de este patio había una plataforma rodeada de cenizas, carbones y abundantes fragmentos de escorias y minerales; gruesas capas de ceniza mezclada con subproductos de la fundición se extendían por todo el suelo del patio. En el interior de la vivienda hay excavado un apéndice en la parte sur en el que apareció gran cantidad de mineral de cobre almacenado.

La plataforma del patio, a la que el Prof. Chernykh (1998: 74) denominó horno metalúrgico por su forma aproximadamente rectangular y su tamaño $(1,5 \times 1 \mathrm{~m})$, no es propiamente la solera de un horno (parece excesivamente grande), pero es sin duda el lugar en el que se reducía el mineral de cobre, no sabemos si mediante pequeñas estructuras construidas sobre ella que eran destruidas y sustituidas tras cada fundición, o como un fuego abierto. Lo cierto es que la arcilla de esta estructura se encuentra rubefactada por haber soportado temperaturas elevadas. También se debió instalar allí la hornilla para calentar los crisoles en los que se fundía el metal, como evidencian las numerosas gotas de cobre halladas en sus proximidades.

Fuera como fuese el horno de reducción (en todo caso una estructura muy simple), podemos saber a través de las escorias cómo era el proceso de formación del metal.Ya hemos dicho que en las escorias hay numerosas bolitas de cobre. La tabla 4 recoge los datos analíticos y podemos ver que las hay de cobre prácticamente puro pero también es frecuente que lleven en disolución algo de hierro (hasta un 2,5\% Fe en el análisis GOR-E25/3) y, desde luego, casi todas ellas, en particular las de mayor tamaño, contienen segregados de óxido y de sulfuro cuproso (Lám. IX).

La formación de sulfuro de cobre es una de las características del método de obtención de cobre en Gorny, pero no debemos entender en modo alguno que estamos proponiendo un método similar al de la mata, comúnmente empleado en la metalurgia actual. A pesar de que, como hemos visto al estudiar los minerales, las fracciones de sulfuros metá-

T. P., 56, n. ${ }^{\circ}$ 2, 1999 


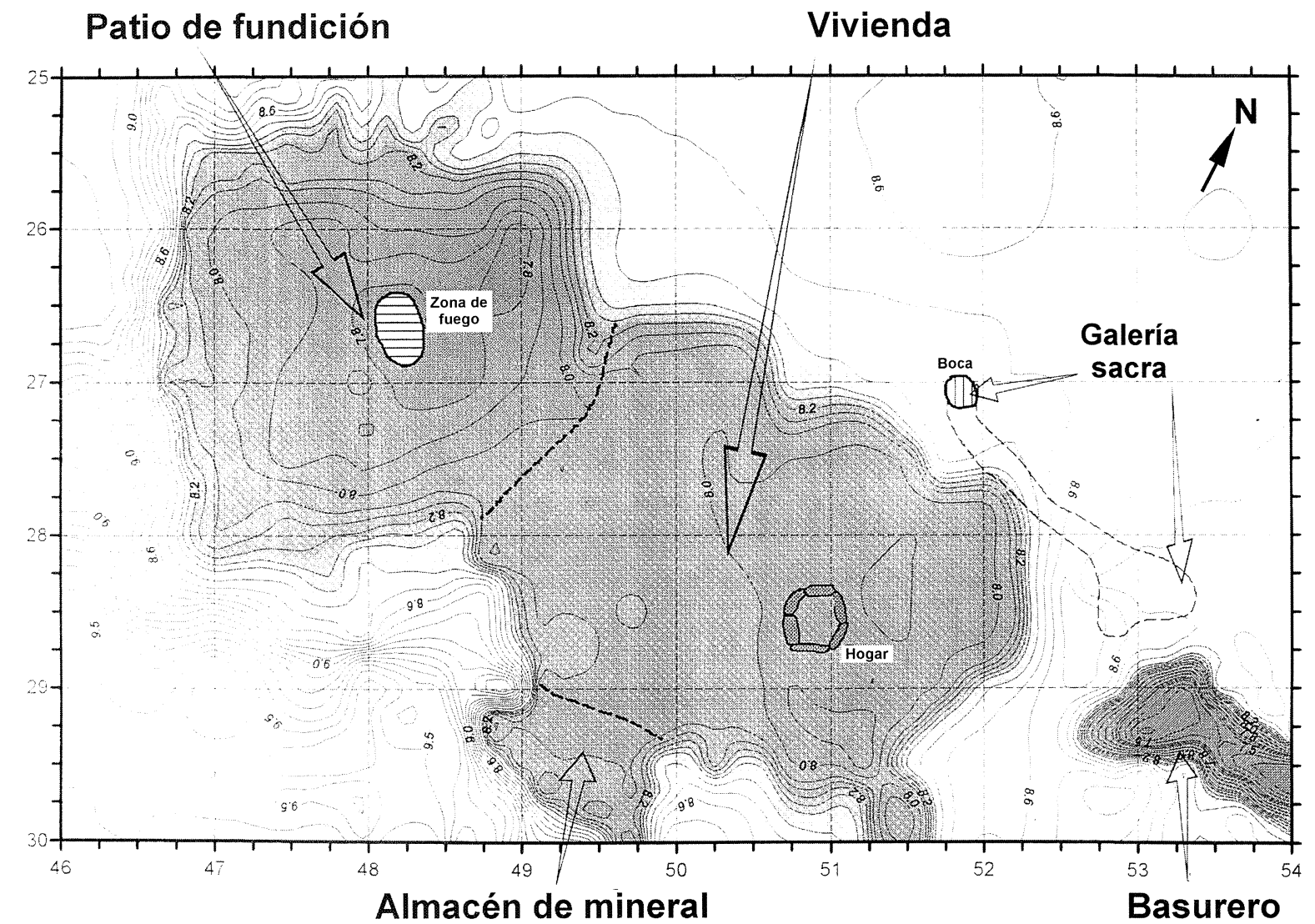

Fig. 4. Planta de la vivienda-taller de la fase B-1 de Gorny, según Chernykh (1998: 74, Fig. 4).

licos en las menas no son cuantitativamente importantes, la baritina y otros sulfatos son en buena medida los responsables de la formación del sulfu-

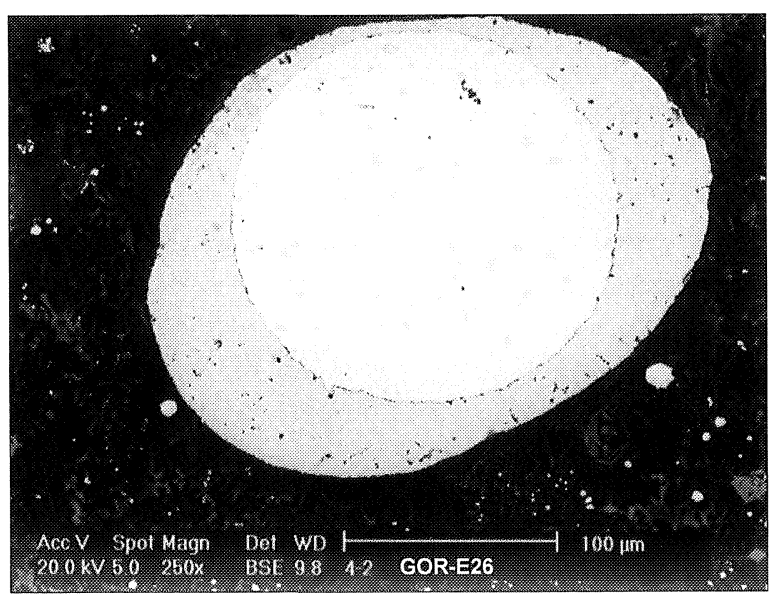

Lám. IX. Imagen obtenida en el MEB con electrones retrodifundidos de la escoria GOR-E26. Detalle de una bola de cobre rodeada de una capa de sulfuro. También hay sulfuro de cobre formando segregados en el interior de la propia bola metálica. ro. Efectivamente, los sulfatos se descomponen en el horno en los óxidos correspondientes. La afinidad del cobre con el azufre es grande (mayor que con el oxígeno) y así, en el ambiente del horno, el cobre reacciona con el azufre formando el sulfuro. No se trata propiamente de mata cuprosa (mezcla de sulfuros de cobre y hierro) porque el poco hierro presente, en exceso de sílice, forma los silicatos de la escoria. En unos casos la oxidación es completa, apareciendo los nódulos de sulfuro. En otros es incompleta y aparecen las esferas de cobre recubiertas por una corona de sulfuro (véase Lám. IX). Entre los materiales excavados es frecuente el hallazgo, junto a goterones y lentejas de cobre, de porciones de sulfuro de similares formas y tamaños, algunos de los cuales han sido analizados y figuran en la tabla 5. En cualquier caso, no podemos decir que la formación de sulfuro en la fundición fuera un efecto pretendido, sino la inevitable consecuencia de la composición de los minerales trabajados.

En este punto llamamos la atención acerca de la errónea idea de que la presencia de cantidades apreciables de azufre en el cobre es síntoma del bene- 


\begin{tabular}{|l|l|l|l|r|r|r|}
\hline \multicolumn{1}{|c|}{ Análisis } & N $^{\circ}$ Invent. & Fase & \multicolumn{1}{c|}{ Objeto analizado } & \multicolumn{1}{c|}{$\mathbf{S}$} & \multicolumn{1}{c|}{ Fe } & Cu \\
\hline GOR-E04/1(1) & $4928-c 6$ & B-2 & Masa amorfa Cu2S & 12,6 & 0 & 87,3 \\
\hline GOR-E04/1(2) & $4928-c 6$ & B-2 & Masa amorfa Cu2S & 17,8 & 0,21 & 81,4 \\
\hline GOR-E17/2 & $4725-g 3$ & B-3 & Masa amorfa Cu2S & 17,0 & 0 & 83,0 \\
\hline GOR-M2 & $295 / 5027$ & B-1 & Nódulo metálico & 0,5 & 0,2 & 99,3 \\
\hline GOR-M4(1) & $303 / 4826$ & B-1 & Nódulo metálico & 0,03 & 0,12 & 99,7 \\
\hline GOR-M4(2) & $303 / 4826$ & B-1 & Masa amorfa metálica & 0,2 & 0,2 & 99,6 \\
\hline
\end{tabular}

Tabla 5. Análisis de restos de fundición de Gorny (Microsonda MEB, \% en peso).

ficio de sulfuros metálicos. Ya Tylecote et alii (1977: 330) denunciaron este hecho, a pesar de lo cual y sin la base analítica adecuada, con excesiva frecuencia se sigue cayendo en el error. Los minerales de Kargaly son básicamente oxídicos y sin embargo la composición de la ganga y el proceso de fundición dan lugar a la formación de sulfuro de cobre (que no de mata cuprosa).

El producto final de la fundición del mineral resulta incierto, a tenor de los datos disponibles. Es evidente que nos hallamos ante hornos muy sencillos en los que la separación cobre-ganga no es buena, pero cuyo rendimiento en metal es más que aceptable. La hipótesis más probable sugiere que del horno saldría una masa de escoria en la que permanecería atrapada la mayor parte del cobre producido, en forma de bolitas y nodulillos de tamaños muy diversos. Algunos, los de mayor tamaño, se habrían desprendido de la masa de escoria y caído a la solera, particularmente si se conseguía formar una escoria de tipo fayalítico. No sabemos con seguridad si se empleaban crisoles para recoger este material, como en Wadi Fidan y Norsun-Tepe, o simplemente se recogían de la parte baja del horno, una vez enfriado. Esta última hipótesis parece la más probable, según podemos deducir de los restos excavados, entre los que no abundan precisamente los crisoles.

También parece evidente que la escoria resultante era machacada para recuperar las bolitas de cobre y de sulfuro de cobre que contenía. Así se hacía en los lugares mencionados y es un procedimiento, por lo que sabemos, de uso común en las fundiciones primitivas no escorificantes (12). Durante las prospecciones en Kargaly se han recogido piedras

(12) En la Península Ibérica, por ejemplo, así se hizo durante el Calcolítico y gran parte de la Edad del Bronce. Véase, entre otros, Gómez Ramos (1999: 76). con cazoleta que pudieron servir de mortero, tanto para minerales como para la escoria. Este proceder podría explicar la inexistencia de los escoriales que serían de esperar en un área de intensa actividad metalúrgica. El polvo de escoria puede haber sido dispersado por los fuertes vientos de la estepa o arrastrado por las aguas suponiendo que la recuperación se hiciera en sencillos lavaderos junto a las corrientes de agua. El yacimiento se encuentra, por cierto, a unos cientos de metros de un arroyo de curso continuo durante todo el año.

El cobre así separado sería fundido en crisoles, obteniendo lingotes planos o planoconvexos, de los que se han encontrado fragmentos en Gorny (Tab. 6). La composición general de estos lingotes no difiere substancialmente de la de las porciones de cobre de la tabla 5, si bien la presencia de bario en uno de ellos está sugiriendo que junto al metal recolectado que ha servido para formarlo había sulfuro de cobre baritado (véanse los análisis GORE04/1(1) y (2) en la Tab. 4), prueba indirecta de que, efectivamente, el sulfuro obtenido en el horno era aprovechado. Las condiciones oxidantes en la hornilla de carbón usada para calentar el crisol a más de $1.100^{\circ} \mathrm{C}$ favorecerían su descomposición. De los dos lingotes (Tab. 6), uno conserva una apreciable cantidad de sulfuro $(0,98 \% \mathrm{~S})$, es decir, que sigue siendo un cobre gris o blister.

La microestructura del lingote GOR-M9 se puede considerar prototípica (Lám. X). Los granos de cobre quedan delineados por grandes segregados globulares de sulfuro (de color gris en la imagen), mientras globulillos de menor tamaño ocupan el interior. El sulfuro de cobre es poco miscible en el cobre, tanto en estado líquido como en sólido, y a poco más de $1.100^{\circ} \mathrm{C}$ precipitan agregados sólidos de sulfuro en un baño de cobre líquido, que son empujados a los bordes de grano conforme va so- 


\begin{tabular}{|c|c|c|c|c|c|c|c|c|}
\hline Análisis & $\mathrm{N}^{\mathbf{0}}$ Inventario & Fase & Región analizada & $\mathbf{O}$ & $\bar{S}$ & $\mathrm{Fe}$ & $\mathrm{Cu}$ & $\mathbf{B a}$ \\
\hline GOR-M17 & $282 / 4928$ & B-1 & Análisis general & -- & 0,06 & 0,1 & 99,8 & 0 \\
\hline GOR-M9 & $87-89 / 5428-\mathrm{a} / 4$ & $\overline{B-3}$ & Análisis general & 0,76 & 0,98 & 0,14 & 97,6 & 0,53 \\
\hline GOR-M9/1 & $87-89 / 5428-a / 4$ & B-3 & Sulfuro segregado & 1,24 & 15,4 & 0,19 & 82,7 & 0,55 \\
\hline GOR-M9/2 & $87-89 / 5428-a / 4$ & B-3 & Sulfuro segregado & 1,04 & 15,2 & 0,07 & 83,2 & 0,5 \\
\hline GOR-M9/3 & $87-89 / 5428-a / 4$ & B-3 & Segregado & 3,1 & 8,1 & 0,1 & 88,4 & 0,27 \\
\hline
\end{tabular}

Tab. 6. Análisis de lingotes de Gorny (Microsonda MEB, \% en peso. --= no analizado. No se han detectado Ni, Zn, As, $\mathrm{Sb}, \mathrm{Sn}, \mathrm{Pb}$ ).

lidificando el metal. A $1.083^{\circ} \mathrm{C}$ tiene lugar una reacción peritética en la que solidifica el líquido residual con un $0,77 \%$ de azufre.

La reducción del sulfuro de cobre a cobre metálico no parece un proceso complejo, según demostraron experimentalmente Zwicker et alii (1980: 137-138) trabajando con minerales sulfurosos sardos. El flujo de aire en la tobera y el tiempo de operación son las variables más importantes a considerar. Las imágenes microscópicas de la serie de escorias y de metal (bolitas embebidas en la escoria) obtenidas en ese experimento se asemejan mucho a las de los materiales de Gorny.

Paloma Uzquiano Ollero (Laboratorio de Arqueobotánica, IH, CSIC) ha identificado las muestras de carbón del yacimiento. Nos interesa mencionar de su estudio aquéllas que tienen una relación directa con el combustible empleado en los procesos metalúrgicos. En su momento le proporcionamos cuatro pequeñas muestras atrapadas en escorias, una de las cuales resultó ser Populus sp. (álamo), otra Be-

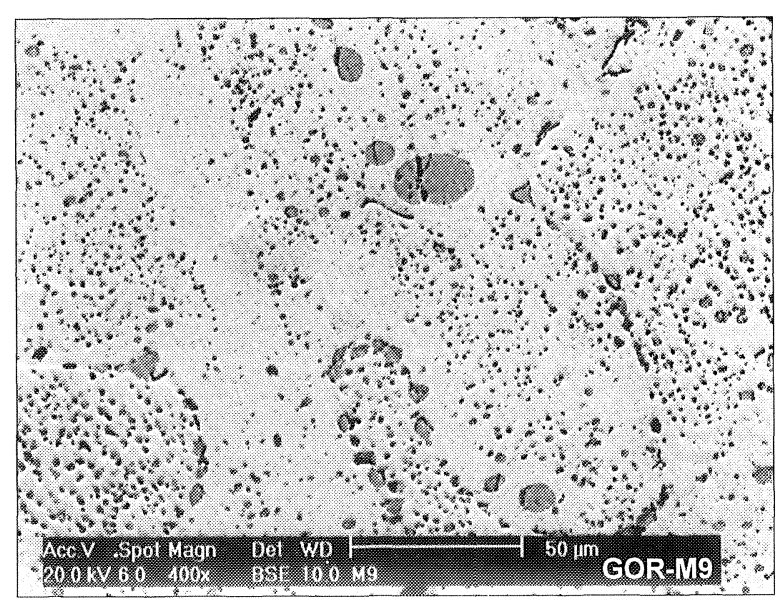

Lám. X. Imagen obtenida en el MEB con electrones retrodifundidos del lingote GOR-M9. Los nódulos grises y los puntos son sulfuro de cobre. tulaceae indet. (familia del abedul), la tercera es hueso carbonizado y la cuarta fue indeterminable. Localizamos una quinta muestra mientras se hacía el estudio por microscopía electrónica de una escoria y, partir de la imagen fotográfica, ha podido ser identificada como perteneciente a un arbusto de la familia de las Rosáceas. De estas determinaciones se deduce que los fundidores de Gorny utilizaban combustibles variados obtenidos de la vegetación de su entorno inmediato, y no sólo carbón de leña de árboles como el abedul o el álamo sino también las ramas de los arbustos. El carbón vegetal, con independencia del árbol de procedencia, tiene un poder calorífico parecido, en torno a las $8.000 \mathrm{kcal} /$ kg (Fluzin, 1983: 20).

\section{LOS OBJETOS DE METAL DE GORNY}

En los talleres de Kargaly se completaba el ciclo metalúrgico con la producción de objetos de cobre de tipología diversa, característicos del elenco de la cultura Srubnaia. Son numerosos los hallazgos de

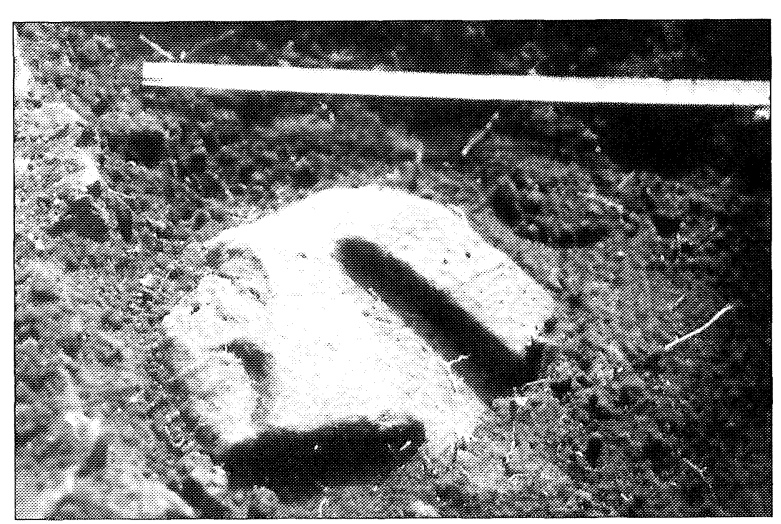

Lám. XI. Fragmento de molde para fundir un pico o martillo de minero, en el momento de ser desenterrado. 


\begin{tabular}{|l|l|l|l|r|r|r|r|r|}
\hline \multicolumn{1}{|c|}{ Análisis } & \multicolumn{1}{|c|}{$\mathbf{N}^{\mathbf{0}}$ Invent. } & Fase & \multicolumn{1}{c|}{ Objeto } & S & Fe & Cu & Sn & Ba \\
\hline GOR-M14 & $326 / 4928-b / 5$ & B-3 & Lámina ondulada & 0 & 0,07 & 99,9 & 0 & 0 \\
\hline GOR-M13(2) & $257 / 5028-a / 5$ & B-3 & Clavo doblado en L & 0,4 & 0,1 & 99,5 & 0 & 0 \\
\hline GOR-M22 & $329 / 5028-d / 6$ & B-2 & Clavo ornamental & 0 & 0,04 & 99,6 & 0 & 0,4 \\
\hline GOR-M20 & $244 / 5028$ & B-1 & Cuchillito & 0 & 0,05 & 99,9 & 0 & 0 \\
\hline GOR-M11 & $275 / 5027-d / 6$ & B-2 & Desecho de taller & 0 & 0,17 & 99,8 & 0 & 0 \\
\hline GOR-M13(3) & $257 / 5028-a / 5$ & B-3 & Desecho de taller & 0,1 & 0,1 & 99,8 & 0 & 0 \\
\hline GOR-M12 & $338 / 5027$ & B-1 & Desecho de taller & 0,1 & 0,3 & 99,6 & 0 & 0 \\
\hline GOR-M10 & $61 / 5129-b / 1$ & B-3 & Desecho de taller (barreta) & 0 & 0,03 & 99,9 & 0 & 0 \\
\hline GOR-M25 & $332 / 5026$ & B-1 & Perforador & 0 & 0,13 & 99,9 & 0 & 0 \\
\hline GOR-M8 & $103 / 5127-c / 4$ & B-3 & Perforador (frag.) & 0,2 & 0,12 & 99,7 & 0 & 0 \\
\hline GOR-M26 & $313 / 5028-a / 3$ & B-3 & Pico de minero (frag.) & 0,2 & 0,12 & 99,7 & 0 & 0 \\
\hline GOR-M7 & $56 / 5127-b / 1$ & B-3 & Placa con borde redondeado & 0,2 & 0,11 & 99,7 & 0 & 0 \\
\hline GOR-M21 & $86 / 5128-a / 4$ & B-3 & Presilla o grapa & 0 & 0,06 & 99,9 & 0 & 0 \\
\hline GOR-M6 & $315 / 4927-c / 4$ & B-3 & Puñal (punta) & 0 & 0,1 & 99,9 & 0 & 0 \\
\hline GOR-M16 & $330 / 5028-d / 6$ & B-2 & Punta de flecha & 0 & 0,1 & 87,2 & 12,6 & 0 \\
\hline GOR-M15 & $163 / 5029-b / 6$ & B-2 & Punzón biapuntado & 0 & 0,05 & 99,9 & 0 & 0 \\
\hline
\end{tabular}

Tab. 7. Análisis de objetos metálicos de Gorny (Microsonda MEB, \% en peso. No se han detectado Ni, Zn, As, Sb, Pb).

moldes bivalvos para fundir hachas, picos, martillos, hoces, puntas y otros objetos (Lám. XI), totalizando 49 ejemplares (Chernyj et alii, 1999: 96) (13). Todos ellos están elaborados sobre bloques de arenisca local, fácil de tallar, y en ninguno se aprecian canales de evacuación de gases ni mazarotas. También se han recogido abundantes desechos de taller, principalmente recortes de metal y gotas caídas del crisol, indicios inequívocos, sobre todo los primeros, de las actividades de producción in situ de objetos metálicos.

La tabla 7 recoge los análisis químicos de una selección de estas piezas y, salvo la punta de venablo GOR-M16, que es de bronce binario, el resto de los materiales son de cobre con impurezas variables de hierro y azufre, es decir, cobres de Gorny. La punta de bronce es un producto extraño a las manufacturas locales, llegado de algún punto de las estepas de Asia central, según la experta opinión de Ye.N. Chernyj (comunicación personal), y es indicio de los contactos a gran distancia que tuvieron lugar durante el largo período de explotación de los recursos cupríferos de Kargaly.

Ninguno de los objetos metalografiados conser-

(13) Estos moldes se distribuyen por fases del siguiente modo: A 2, B-1 13, B-2 9, B-3 25. va intacta la estructura de fundición. Las piezas, después de ser sacadas del molde, fueron trabajadas a martillo en frío en mayor o menor grado según su función. Un ejemplo evidente es el fragmento GOR-M6 correspondiente a la punta afilada de un puñal. La lámina XIIA muestra la estructura metálica en la zona central de la hoja, en la que se aprecia la retícula de granos formados durante la solidificación del cobre en el molde, según un proceso de enfriamiento lento propiciado por las buenas condiciones refractarias y de aislamiento térmico del molde de arenisca, probablemente reforzadas por el calentamiento previo del propio molde para facilitar la colada. Esta estructura está ligeramente deformada por golpes de martillo que han aplastado levemente los granos produciendo una cierta orientación. En la parte del filo la acción del martilleo en frío ha sido mucho más intensa y como consecuencia de ello los granos se encuentran muy deformados por un notable estiramiento (Lám. XIIB) que todavía es mayor en el propio filo. No hay duda de que el metalúrgico trabajó de manera muy consciente el metal para conseguir en el puñal unos filos duros, cortantes (aunque frágiles), mientras que en el interior de la hoja un cobre más maleable proporcionaba al conjunto la capacidad de resistir una cierta deformación sin romperse. 

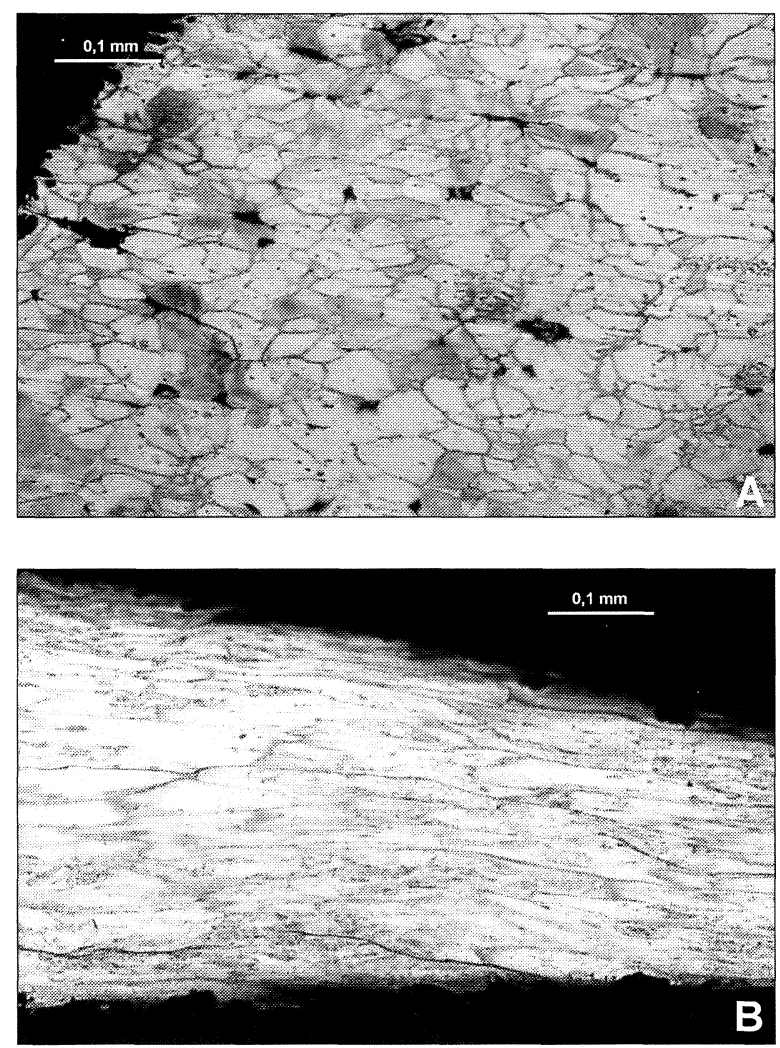

Lam. XII. Metalografías de la sección del puñal GORM6. A: zona del centro de la hoja. Retícula producida por el enfriamiento lento de la colada metálica, ligeramente deformada por la acción de una leve forja en frío que ha provocado una cierta orientación de los granos. B: zona del filo. Obsérvese la deformación de los granos (estiramiento) debida a un intenso trabajo de forja en frío.

Otro tratamiento metalúrgico muy frecuente es el recocido del metal con posterioridad al trabajo de forja. Lo apreciamos en un pico de minero (Lám. XIII), entre otros objetos de naturaleza masiva. El recocido provoca la recristalización del cobre y corrige las tensiones internas introducidas por las deformaciones mecánicas al forjar el metal. La nueva estructura, formadas por cristales de hábito poliédrico más o menos maclados (líneas paralelas) es más resistente al choque. Esto es especialmente útil en un cobre blister con abundantes inclusiones de sulfuro de cobre $(0,2 \% \mathrm{~S}$ en el análisis GOR-M26 de la Tab. 7), ya frágil de por sí. Este tratamiento térmico se aplicaba también a los objetos laminares en las distintas fases de la laminación en frío, pues el metal severamente deformado por martilleo se hace frágil y duro, y es necesario recuperarlo por medio de recocidos pues de lo contrario se rompería.

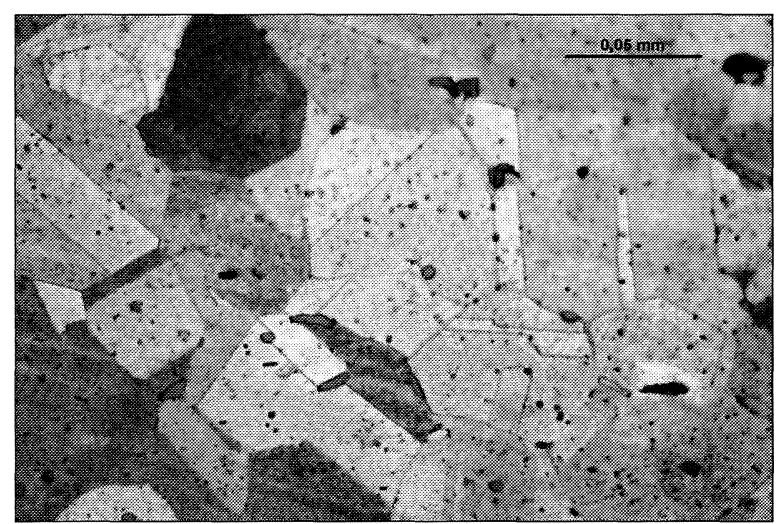

Lám. XIII. Metalografía de un pico de minero. Estructura de cobre forjado en frío y recocido: granos de sección poligonal maclados. La colada es sucia, con abundantes impurezas (picaduras), glóbulos de sulfuro de cobre (gris oscuro) y micro-rechupes o burbujas gaseosas, aplastados al forjar el metal.

\section{EL COBRE DE KARGALY EN TIEMPOS MODERNOS}

Hacia el siglo XIII a.C. el distrito minero de Kargaly fue misteriosamente abandonado y su memoria, al parecer, se pierde hasta el siglo XVIII cuando Iván Tverdishev, señor de vidas y haciendas, vuelve a poner en explotación las minas en 1745 (Chernij, 1995: 34). En esta segunda etapa, que duraría hasta finales del siglo XIX, se extrajeron 115.000 Tm de cobre, según las fuentes consultadas por Chernyj.

Nos interesa destacar aquí dos aspectos, por su interés para entender la metalurgia del pasado más remoto. En primer lugar, las fundiciones se instalaron en Bashkiria, en la zona boscosa de los Urales del sur, donde el aprovisionamiento de combustible era seguro, distante unos $300 \mathrm{~km}$ de Kargaly. El mineral extraído era, pues, transportado esa distancia en carros y trineos, según la estación.

En segundo lugar, y a pesar de lo avanzado de la época, la obtención de cobre no parece que resultara sencilla. Hemos tenido ocasión de realizar una somera prospección por las ruinas de las fundiciones de Voskresesnskoye y Verkhoter, rodeadas de enormes extensiones de escoriales. Durante el rápido paseo por los amontonamientos de escorias no percibimos diferencias morfológicas significativas entre estos materiales de desecho, lo que nos hace pensar que la tecnología de fundición no parece que cambiara demasiado a lo largo de los 150 años de vida de estas instalaciones industriales. 
Las escorias son todas de sangrado, de aspecto vítreo de vivos colores. Las muestras recogidas de diversos puntos tienen una composición poco homogénea (Tab. 8) que se caracteriza grosso modo por ser pobre en hierro (en general) y rica en calcio. La representación de sus composiciones globales en el diagrama de equilibrio de fases se muestra en la figura 5. Si la comparamos con la figura 3 correspondiente a las escorias arqueológicas observaremos un claro desplazamiento de algunos puntos hacia la izquierda porque esas escorias de Bashkiria contienen todavía menos hierro que las de Gorny, mientras que otros puntos comparten el mismo campo que aquéllas; los contenidos de calcio son similares en ambos conjuntos. Es sorprendente pero los metalúrgicos rusos de los siglos XVIII y XIX no habían avanzado un ápice en relación con los del Bronce Final de Gorny para conseguir escoria de bajo punto de fusión. Se seguían fundiendo los minerales directamente, sin añadir fundentes, pero eso sí, en hornos mucho más evolucionados que permitían alcanzar y mantener las altas temperaturas necesarias para fundir la escoria (por encima de los $1.300^{\circ} \mathrm{C}$ ), que sobreañadiría el baño de cobre líquido y podía ser sangrada en el momento oportuno. Todo ello a base de un superconsumo de carbón vegetal. Con carbón mineral, ni aun de la calidad de la buena antracita, probablemente no se hubiera podido obtener cobre de forma rentable porque su capacidad calórica es sensiblemente inferior al carbón de mandera. Sólo cabe pensar que la búsqueda e importación de óxido de hierro, el fundente ideal

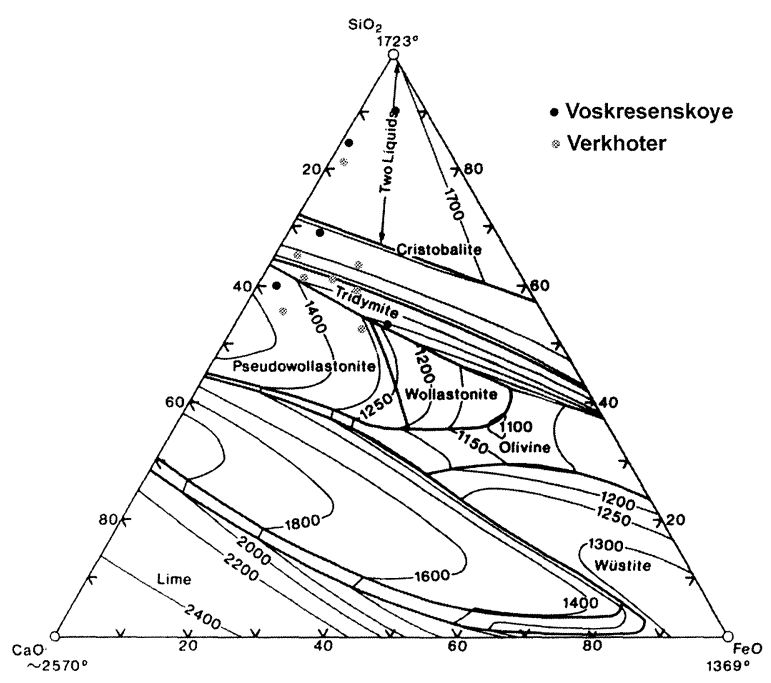

Fig. 5. Diagrama de equilibrio de fases de las escorias modernas de Bashkiria. para conseguir una buena escorificación a baja temperatura, resultaron infructuosas o más onerosas que el consumo en exceso de carbón.

La retención de cobre en las escorias de Bashkiria es baja. Muchos de los análisis generales arrojan una cifra 0 que, dada la sensibilidad de la microsonda en este tipo de análisis, debe interpretarse del orden de algunas décimas por ciento. En otras muestras se han medido porcentajes del orden del $2,5 \mathrm{al} 3 \%$, una pérdida elevada para un horno moderno.

Otro aspecto que acerca la metalurgia reciente a la de la Edad del Bronce es que el metal obtenido contiene cantidades apreciables de sulfuro de cobre. Se han analizado muestras tomadas de dos grandes masas de cobre tiradas en los escoriales cuya composición encaja sin dificultad en los cobres de Gorny.

\section{8. , METALURGIA EXPERIMENTAL EN KARGALY}

Los materiales pirometalúrgicos de Gorny permiten trazar un panorama coherente (aunque no exento de puntos oscuros) de la tecnología puesta en juego para la obtención y el trabajo del cobre. Había, sin embargo, ciertos aspectos llamativos sobre los que convenía experimentar con el fin de llegar a un conocimiento más profundo y, sobre todo, obtener datos de algunas variables económicas que nos permitieran una mejor aproximación al modelo global de explotación.Aunque no vamos a entrar de forma detallada en la descripción de la vía experimental, que será objeto de futuros trabajos, usaremos aquí algunos de sus resultados de orden práctico.

Un primer aspecto a determinar era si la formación de escorias de alto punto de fusión, superior a los $1.400^{\circ} \mathrm{C}$ según el diagrama de fases (véase la Fig. 3), es posible utilizando un horno metalúrgico sencillo. La respuesta es afirmativa, si bien la temperatura de formación de la escoria es notablemente más baja que la teórica antes mencionada. Se probaron dos tipos de horno: simples hoyos en el suelo de 30,20 y $15 \mathrm{~cm}$ de diámetro y similar profundidad, sin ningún revestimiento especial (Lám. XIVA), y dos hornos cilíndricos con paredes de piedra arenisca trabada con barro, de unos $40-50 \mathrm{~cm}$ de diámetro y unos $30-40 \mathrm{~cm}$ de altura útil en la cámara (14) (Lám. XIVB). Se utilizaron dos fuelles de 30 litros de capacidad cada uno que alimentaban dos toberas de cerámica con boquilla de $10 \mathrm{~mm}$ de paso, excepto en el último experimento que fueron

T. P., 56, n. ${ }^{\circ} 2,1999$ 


\begin{tabular}{|c|c|c|c|c|c|c|c|c|c|c|c|c|}
\hline Análisis & Región analizada & $\mathrm{FeO}$ & $\mathrm{Al}_{2} \mathrm{O}_{3}$ & $\mathrm{SiO}_{2}$ & $\mathrm{CaO}$ & MgO & $\mathbf{B a O}$ & $\mathrm{K}_{2} \mathrm{O}$ & $\mathrm{TiO}_{2}$ & $\mathrm{CuO}$ & SO & $\mathbf{P}_{2} \mathbf{O}_{5}$ \\
\hline IBAS1-3 & Grano sílice & 0 & 0 & 100 & 0 & 0 & 0 & 0 & 0 & 0 & 0 & 0 \\
\hline 1BAS1-4 & Inclusión óxido & 62,6 & 0,6 & 11,8 & 0 & 0 & 0 & 0 & () & 17.7 & 0 & 6,2 \\
\hline 1BAS1-5 & Vetas en grano sílice & 0 & 0 & 8,6 & 0,6 & 0 & 0 & 1,1 & 0,6 & 89 & 0 & () \\
\hline IBAS1-6 & General & 1,6 & 6,8 & 57,9 & 25,4 & 1,41 & 0 & 3.1 & 1.6 & 2.1 & () & $\overline{0}$ \\
\hline 1BAS2-2 & Fase gris clara & 0 & 6,7 & 63,4 & 25,2 & 1,2 & 0 & 2.3 & 1.1 & 0 & 0 & $\overline{0}$ \\
\hline 1BAS2-3 & Fase gris oscura & 0 & 0 & 100 & 0 & 0 & 0 & 0 & 0 & 0 & () & 0 \\
\hline 1BAS2-4 & General & 1,5 & 4,8 & 77,3 & 12,2 & 0 & 0 & 1.7 & 0.9 & 1.7 & 0 & $\overline{0}$ \\
\hline 1BAS3-2 & Zona gris clara & 1 & 0 & 4,3 & 1,1 & 0 & 0 & 0.2 & 0 & 93,3 & 0 & $\overline{0}$ \\
\hline IBAS3-3 & Zona gris intermedia & 0 & 0 & 0 & 100 & 0 & 0 & 0 & 0 & () & () & $\overline{0}$ \\
\hline 1BAS3-4 & Granos sílice & 0 & 0 & 100 & 0 & 0 & 0 & 0 & 0 & 0 & 0 & $\overline{0}$ \\
\hline 1BAS3-5 & General & 3,3 & 2,2 & 51,8 & 2,9 & 0 & 0 & 0 & 0 & 39.6 & 0 & $\overline{0}$ \\
\hline IBAS4-3 & Aguja cristalina & 2,1 & 2,5 & 48,7 & 39,9 & 0 & 0 & 5,2 & () & 0 & 0 & 1.5 \\
\hline IBAS4-4 & Matriz vítrea & 6,5 & 2,8 & 65,4 & 14,6 & 0 & 0 & 13,2 & 1.6 & 0 & 0 & 1.9 \\
\hline 1BAS5-1 & Inclusión oscura & 72,5 & 0 & 2,2 & 0 & 0 & 0 & 0 & 0 & 7.8 & 0 & 16.1 \\
\hline 1BAS5-2 & Glóbulo gris claro & 6 & 0 & 0 & 0 & 0 & 0 & 0 & () & 73,8 & 20,2 & $\overline{0}$ \\
\hline 1BAS5-3 & Matriz gris nódulo & 79,2 & 0 & 1,7 & 0 & 0 & 0 & 0 & 0 & 1.3 & 0 & 16.7 \\
\hline 1BAS5-4 & Inclusiones blancas nódulo & 30,8 & 0 & 3,1 & 0 & 0 & 0 & 0 & 0 & 58.2 & 0 & 6.9 \\
\hline 1BAS6-1 & Inclusión en grano $\mathrm{Cu}$ & 84 & 0 & 0 & 0 & 0 & 0 & 0 & () & 3,2 & () & 12,8 \\
\hline 1BAS6-3 & Inclusión en grano $\mathrm{Cu}$ & 83,8 & 0 & 0 & 0 & 0 & 0 & 0 & 0 & 2.7 & 0 & 13.4 \\
\hline 1BAS6-5 & Inclusión en grano $\mathrm{Cu}$ & 82,2 & 0 & 0 & 0 & 0 & 0 & 0 & 0 & 3,6 & 0 & 14.2 \\
\hline 1BAS6-6 & General & 2,3 & 7,1 & 51,2 & 33 & 1,4 & 0 & 3,4 & 1,5 & 0 & () & $\overline{0}$ \\
\hline 1BAS7-3 & General & 4 & 4,5 & 62,42 & 14,6 & 0,7 & 0 & 11.3 & 0 & 2.5 & 0 & $\overline{0}$ \\
\hline 1BAS8-2 & General & 18,5 & 4,7 & 50,5 & 22,9 & 0 & 0 & 3,4 & 0 & 0 & 0 & $\overline{0}$ \\
\hline $2 \mathrm{BASI}-1$ & Inclusión en grano $\mathrm{Cu}$ & 88,8 & 0 & 0 & 0 & 0 & 0 & 0 & 0 & 2,6 & 0 & $\overline{8,6}$ \\
\hline $2 \mathrm{BASI}-3$ & General & 10 & 6,4 & 55,2 & 25,2 & 0 & 0 & 3.2 & 0 & 0 & 0 & 0 \\
\hline 2BAS2-2 & General & 4,1 & 6,9 & 52,63 & 29,6 & 1,3 & 0 & 2,8 & 0 & 2.7 & 0 & $\overline{0}$ \\
\hline 2BAS3-3 & General & 17,7 & 4,9 & 54,2 & 21 & 0 & 0 & 2,2 & 0 & 0 & 0 & $\overline{0}$ \\
\hline 2BAS4-1 & Bolita hierro & 91,5 & 0 & 0 & 0 & 0 & 0 & 0 & 0 & 3.4 & 0 & 5.2 \\
\hline 2BAS4-2 & General & 3,2 & 7,4 & 57,5 & 27,5 & 1,5 & 0 & 2.8 & 0 & 0 & () & 0 \\
\hline 2BAS4-3 & Inclusión en grano $\mathrm{Cu}$ & 90,3 & 0 & 0 & 0 & 0 & 0 & () & () & 2.6 & () & 6 \\
\hline 2BAS5-2 & Zona gris & 1 & 0 & 0 & 0 & 0 & 0 & 0 & () & 99 & 0 & 0 \\
\hline 2BAS5-3 & Grano sílice & 0 & 0 & 100 & 0 & 0 & 0 & 0 & 0 & 0 & 0 & $\overline{0}$ \\
\hline 2BAS5-4 & Grano sílice & 0 & 0 & 100 & 0 & 0 & 0 & 0 & 0 & () & 0 & 0 \\
\hline 2BAS5-5 & Corona grano sílice & 0 & 6,5 & 64,6 & 21,3 & 0,8 & 0 & 1.9 & 0 & 4.9 & () & $\overline{0}$ \\
\hline 2BAS5-6 & Corona grano sílice & 0 & 7 & 60,2 & 25 & 1,2 & 0 & 1,8 & 0 & 4,8 & 0 & 0 \\
\hline 2BAS5-7 & Zona gris intermedia & 0 & 6,8 & 67,6 & 21,7 & 1,1 & 0 & 1,7 & 0 & 1.4 & () & 0 \\
\hline 2BAS5-9 & Grano sílice & 0 & 0 & 100 & 0 & 0 & 0 & 0 & 0 & 0 & 0 & $\overline{0}$ \\
\hline 2BAS5-10 & Zona gris clara & 0 & 7,1 & 66 & 22,2 & 1,2 & 0 & 2,1 & 1,37 & () & 0 & $\overline{0}$ \\
\hline $2 B A S 5-11$ & General & 2,5 & 5,2 & 72,6 & 13,3 & 0,8 & 0 & 1,7 & 1 & 3 & 0 & $\overline{0}$ \\
\hline 2BAS6-3 & Matriz & 4,9 & 7 & 49,9 & 33,7 & 0 & 0 & 3.2 & 1.3 & 0 & 0 & $\overline{0}$ \\
\hline 2BAS6-4 & General & 4,8 & 7,4 & 48,7 & 34,1 & 0 & 0 & 3.3 & 1,7 & () & 0 & 0 \\
\hline 2BAS7-3 & General & 22,8 & 4,9 & 49,3 & 20,2 & 0 & 0 & 2,7 & () & () & () & $\overline{0}$ \\
\hline 2BAS7-4 & General & 24,5 & 5,4 & 47,1 & 20,4 & 0 & 0 & 2.5 & 0 & () & 0 & $\overline{0}$ \\
\hline 2BAS8-2 & Zona gris oscura & 90,5 & 0 & 6,6 & 0 & 0 & 0 & 0 & 0 & 2.9 & 0 & 0 \\
\hline 2BAS8-3 & Zona gris intermedia & 83,2 & 0 & 4 & 0 & 0 & 0 & 0 & 0 & 4.7 & () & 8.1 \\
\hline 2BAS8b-3 & General & 14,8 & 6,6 & 55,1 & 17,3 & 0,9 & 0 & 2.7 & 0 & 2.6 & 0 & $\overline{0}$ \\
\hline
\end{tabular}

Tab. 8. Análisis de escorias modernas de Bashkiria (Microsonda MEB, \% en peso de óxidos). 

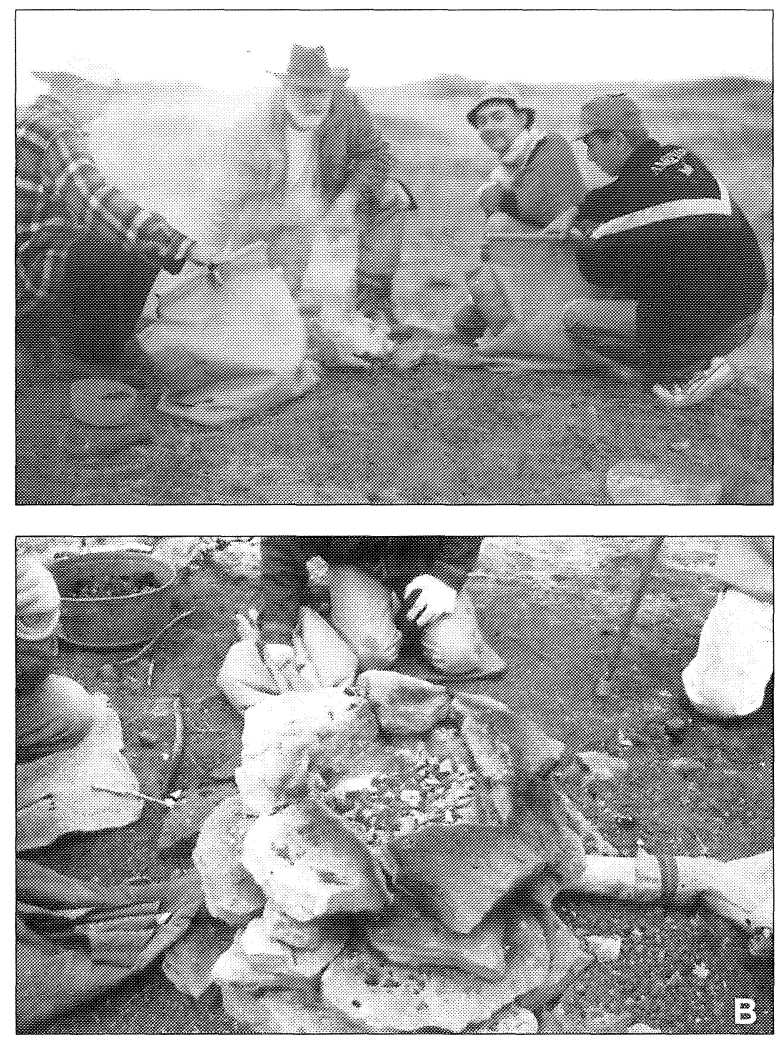

Lám XIV. A: Experimento de fundición de minerales de cobre en Gorny (1998). El horno es una simple cubeta de unos $20 \mathrm{~cm}$ de diámetro máximo y otros tantos de profundidad, excavada en el suelo. La ventilación forzada es proporcionada por dos fuelles y dos toberas calzadas con piedras. B: Horno cilíndrico de mampostería utilizado en el experimento $\mathrm{n}^{\circ} 5$.

tres los fuelles y las toberas más abiertas, unos 25 mm de diámetro en la boquilla, y en el primero, aireado por la corriente natural del viento penetrando por tres ventanillas abiertas en la base del horno. Las características de los hornos experimentales se dan a continuación:

1. Horno cilíndrico de mampostería.Altura 50 $\mathrm{cm}$, diámetro $40 \mathrm{~cm}$. Ventilación por corriente natural de aire.

2. Cubeta excavada en el suelo. Profundidad $30 \mathrm{~cm}$, diámetro $30 \mathrm{~cm}$. Ventilación con dos fuelles $\mathrm{y}$ dos toberas.

3. Cubeta excavada en el suelo. Profundidad $25 \mathrm{~cm}$, diámetro $25 \mathrm{~cm}$. Ventilación con dos fuelles y dos toberas.

(14) El último de los experimentos de fundición de mineral fue realizado en un horno cilíndrico construido por Jacques Happ, con cuya colaboración llevamos a cabo la parte final de la experimentación.
4. Cubeta excavada en el suelo. Profundidad $15 \mathrm{~cm}$, diámetro $15 \mathrm{~cm}$. Ventilación con dos fuelles y dos toberas.

5. Horno cilíndrico de mampostería. Altura 40 $\mathrm{cm}$, diámetro $40 \mathrm{~cm}$. Ventilación con tres fuelles y tres toberas.

Para los experimentos se recogieron fragmentos de malaquita y azurita de los alrededores de Gorny, seleccionando aquellos que por sus colores más vivos indicaban una mayor riqueza en cobre. Fueron triturados con martillos sobre durmientes de piedra hasta reducirlos a porciones de unos $2-3 \mathrm{~mm}$ como máximo (Lám. XV).

La puesta en operación de los hornos consistió en una primera fase de precaldeo, de algo más de media hora, durante la cual el carbón vegetal se hacía arder hasta su máximo brillo (brasas de color amarillo-blanco) ayudado por un accionamiento suave de los fuelles, y las paredes del horno tomabań un color rojo cereza en las partes bajas. A partir de ese momento se iniciaba la fundición propiamente dicha, agregando un puñado de mineral humedecido para evitar la pérdida de polvo, repartido más o menos homogéneamente sobre las brasas, que se tapaba inmediatamente con carbón desmenuzado. Conforme se iba consumiento el carbón de la superficie estaba incandescente, se añadía más mineral y carbón de la manera que se ha indicado, hasta completar el ciclo. Tras la última carga se seguía añadiendo carbón durante una media hora y luego se dejaba que se fuera consumiendo.

Los fuelles eran accionados simultáneamente, de manera que se producían periodos de gran ventilación de unos 5 segundos de duración, mientras se descargaban los fuelles, en los que la atmósfera en la cámara es más oxidante y la temperatura se eleva, seguidos de periodos de carencia para llenar los

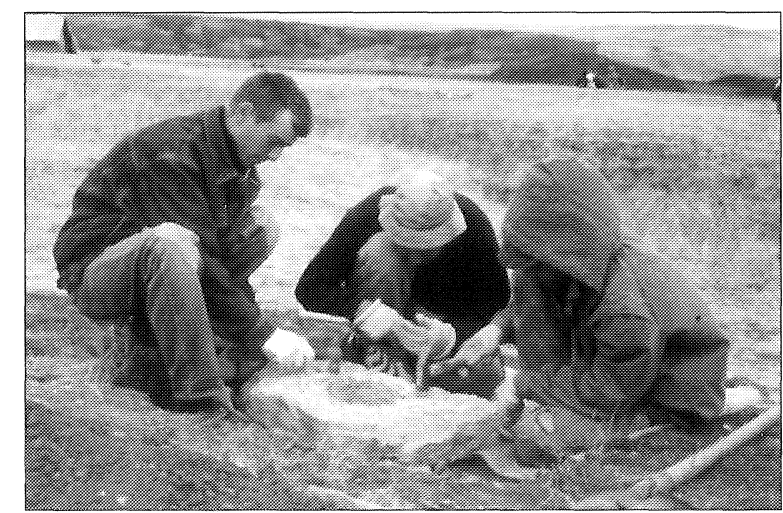

Lám. XV. Operación de machacado del mineral. 
fuelles, de unos 2-3 segundos, en los que el ambiente es reductor y la temperatura desciende notablemente. Cuando comenzaba a aflorar la masa de escoria se interrumpía la ventilación y se dejaba apagar y enfriar el horno.

En todos los experimentos de fundición de mineral se obtuvo un bloque de escoria de características similares: un material ligero, esponjoso, con numerosas bolitas de cobre atrapadas cuyos diámetros oscilan entre 3-4 mm y tamaño microscópico (Lám. XVI). Se formó una cantidad en torno al 10\% de sulfuro de cobre. La composición y estructura de estas escorias no difieren significativamente de las arqueológicas pero son menos densas y más homogéneas (Tab. 9). Al representar los análisis en el diagrama ternario $\mathrm{CaO}-\mathrm{FeO}-\mathrm{SiO}_{2}$ observamos que todas caen en la región de las temperaturas más elevadas, junto con el primer grupo de las escorias arqueológicas comentado antes (Fig. 6).

Aunque no pudimos disponer de ningún pirómetro para la medición precisa de temperaturas en el horno, la escala de colores que tomaban ciertos materiales del hogar por el impacto térmico resultaron buenos indicadores. Además, los efectos de las altas temperaturas quedaban reflejados en la formación de vidriados y escorificaciones apreciables cuando el horno se enfriaba. Uno de estos efectos fue el vidriado e incluso fundición de las boquillas de las toberas, fabricadas con material refractario (arcilla con desgrasante de cuarzo), como muestra elocuentemente la lámina XVII.

Dado que en ninguno de los experimentos se consiguió separar cobre de la escoria en el horno, hay que pensar que todo el cobre existente en el mineral de origen se encuentra en la escoria como cobre metálico y compuestos de cobre no reducidos.

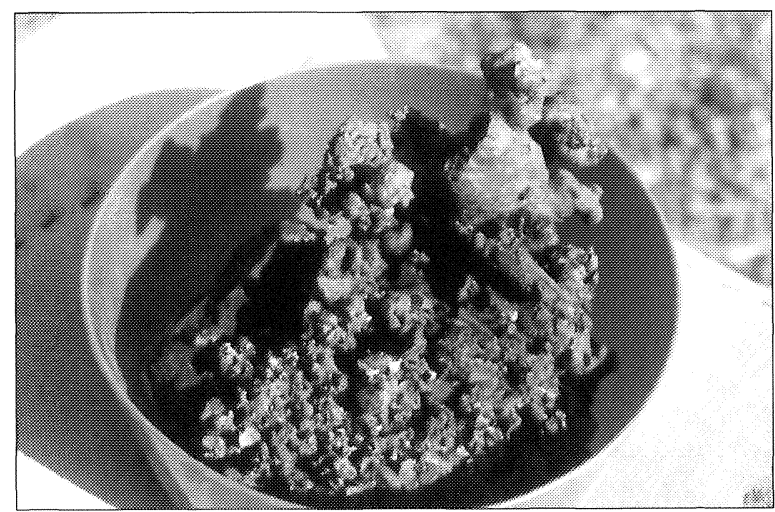

Lám. XVI. Bloque de escoria obtenido en el experimento $n^{\circ} 2$.

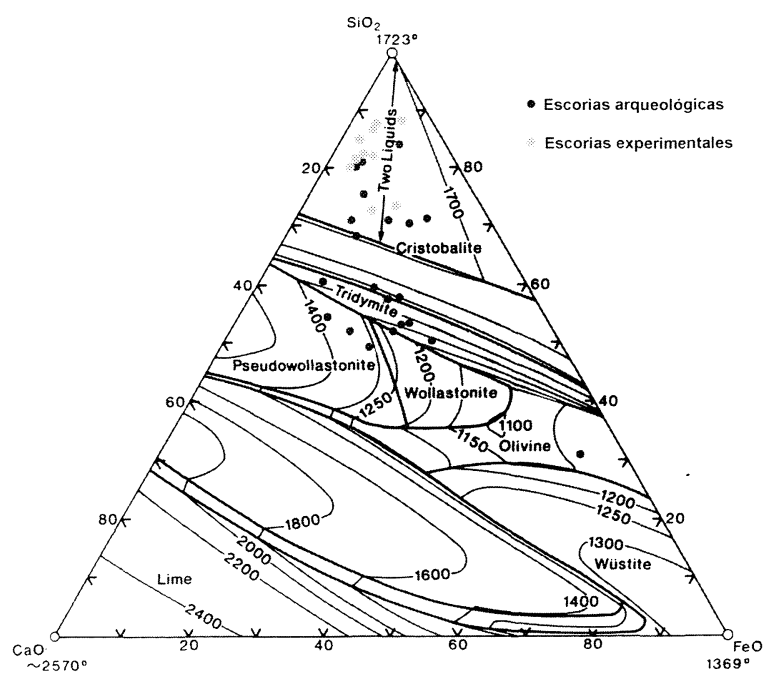

Fig. 6. Diagrama de equilibrio de fases de las escorias arqueológicas y experimentales de Gorny. Obsérvese al agrupamiento de estas últimas dentro de uno de los grupos de escorias arqueológicas.

Tomando como referencia de cálculo los datos del último experimento $\left(\mathrm{n}^{\circ} 5\right)$, la cantidad media de cobre en la escoria es del $8,6 \%$, medido como $\mathrm{CuO}$, lo que equivale a un $6,9 \%$ de cobre metálico.Teniendo en cuenta las pérdidas en los humos de elementos del mineral (principalmente carbono y oxígeno), la riqueza en cobre del mineral, calculada a partir de la escoria, es aproximadamente del $6 \%$, dato que contrasta con los análisis de algunas muestras de mineral empleado en el experimento, señaladas como EXGOR5 en la tabla 1, cuya riqueza media es del $28 \% \mathrm{CuO}(22 \% \mathrm{Cu})$. Ello significa que las muestras analizadas no son representativas del conjunto de minerales fundidos (15), lo cual resta credibilidad a los cálculos teóricos sobre rendimiento realizados anteriormente en el apartado de las escorias arqueológicas, si bien la cifra en torno al $9 \% \mathrm{Cu}$ remanente en la escoria arqueológica resulta bastante concordante con la obtenida experimentalmente $(6 \% \mathrm{Cu})$ e indica dos cosas: que, en general, las fundiciones prehistóricas se hicieron con minerales menos ricos que los seleccionados para su análisis y que los cálculos de rendimiento no pueden efectuarse de manera fiable comparando las analíticas de minerales y escorias, porque son las escorias en sí mismas las que contienen retenido el cobre metálico

(15) Efectivamente, no se trata de muestras escogidas aleatoriamente, sino seleccionadas por sus colores más vivos, indicativos de una mayor riqueza metálica. 


\begin{tabular}{|c|c|c|c|c|c|c|c|c|c|c|c|c|}
\hline Análisis & Región analizada & $\mathrm{FeO}$ & $\mathrm{Al}_{2} \mathrm{O}_{3}$ & $\mathrm{SiO}_{2}$ & $\mathrm{CaO}$ & $\mathrm{MgO}$ & $\mathrm{BaO}$ & $\mathrm{K}_{2} \mathrm{O}$ & $\mathrm{TiO}_{2}$ & $\mathrm{CrO}$ & $\mathrm{CuO}$ & SO \\
\hline EXGOR1/E1-2 & Agujas melilita? & 3,46 & 2,35 & 34,47 & 1.84 & 5.86 & $\overline{0}$ & 0 & 0 & 0 & 52.01 & 0 \\
\hline EXGOR1/E1-3 & Relleno melilita? & 1,58 & 21,91 & 61,48 & 10,16 & 0,76 & 0 & 0 & () & () & 4.11 & 0 \\
\hline EXGOR1/E1-4 & Granos blancos & 1,28 & 0,72 & 0,73 & 0,18 & 0,31 & 0 & 0 & () & () & 96.78 & 0 \\
\hline EXGOR1/E1-5 & Inclusión & 0 & 0 & 100 & 0 & 0 & 0 & 0 & 0 & () & () & 0 \\
\hline EXGOR1/E1-6 & General & 3,31 & 9,44 & 54,71 & 2,08 & 1,07 & 0 & 1,51 & 1.49 & () & 26.44 & 0 \\
\hline EXGOR1/E2-1 & General sin metal & 8 & 5,6 & 58,4 & 12,3 & 0,8 & 0 & 2.4 & 2.6 & 0 & 10 & 0 \\
\hline EXGOR1/E2-2 & General con metal & 6,7 & 4,1 & 43,6 & 2,9 & 0 & 0 & 1.1 & 1 & (0) & 37.3 & 3.3 \\
\hline EXGOR1/E3-1 & Grano $\mathrm{Fe} \mathrm{Cr}$ & 32,4 & 5,7 & 0 & 0 & 2,3 & 0 & 0 & (0) & 59.5 & 0 & 0 \\
\hline EXGOR1/E3-2 & Iincl. Ovalada & 72,8 & 4,8 & 13,9 & 2 & 1,9 & 0 & 1.9 & 2.6 & (0) & (0) & 0 \\
\hline EXGOR 1/E3-3 & Melilita? & 3,4 & 13,2 & 67,5 & 4,2 & 0 & 0 & 11.7 & 0 & () & (0) & 0 \\
\hline EXGOR1/E3-4 & General & 12,3 & 10,8 & 63,5 & 7,1 & 0 & 0 & 4,8 & 1.4 & () & 0 & () \\
\hline EXGOR2/E1-10 & Matriz piroxeno & 4 & 9,4 & 59,9 & 17,3 & 0 & 3,5 & 3.3 & 0 & 0 & 2.5 & () \\
\hline EXGOR2/E1-6 & Grano sílice & 0 & 0 & 100 & 0 & 0 & 0 & 0 & 0 & 0 & 0 & 0 \\
\hline EXGOR2/E1-8 & Agujas melilita? & 1,8 & 17,8 & 56,9 & 1,1 & 0 & 16.7 & 5.7 & () & () & (0) & 0 \\
\hline EXGOR2/E1-9 & General con metal & 1,9 & 8,3 & 58,8 & 3,8 & 0 & 2.1 & 3.4 & () & () & 21.7 & 0 \\
\hline EXGOR3/E1-1 & Aguja melilita & 9,3 & 7,6 & 56,7 & 17,2 & 4,7 & 0 & 1,6 & 0 & 0 & 2.8 & 0 \\
\hline EXGOR3/E1-2 & Zona entre agujas & 5,1 & 12,1 & 65 & 4,2 & 0,66 & 3,9 & 3,2 & () & () & 5.9 & 0 \\
\hline EXGOR3/E1-3 & Grano sílice & 0 & 0 & 100 & 0 & 0 & 0 & () & () & () & 0 & 0 \\
\hline EXGOR3/E1-7 & Matriz piroxeno & 11,3 & 6,4 & 48,2 & 16,2 & 2,9 & 4 & 2,8 & 0 & () & 8.2 & 0 \\
\hline EXGOR3/E1-8 & General con metal & 3,1 & 8,2 & 62,1 & 4,6 & 1,4 & 2,1 & 1,9 & () & () & 16.6 & () \\
\hline EXGOR4/E1-3 & Matriz piroxeno & 3,7 & 7 & 54,8 & 22,9 & 1,2 & 0,73 & 2.2 & 1.4 & 0 & 5,4 & 0.63 \\
\hline EXGOR4/E1-4 & General & 2,6 & 6,4 & 65,2 & 10,4 & 0,72 & 2.1 & 1.9 & 0.36 & 0 & 9.9 & 0.3 \\
\hline EXGOR4/E2-1 & Dendritas cuprita & 2,3 & 3 & 19,1 & 1,7 & 0 & 0,39 & 0,79 & 0.57 & () & 71,9 & 0,16 \\
\hline EXGOR4/E2-2 & Dendritas cuprita & 2,6 & 3,3 & 23 & 2,1 & 1 & 0,86 & 0.44 & 0.17 & 0 & 66 & 0.44 \\
\hline EXGOR4/E2-3 & Piroxeno & 11,6 & 6,6 & 55,3 & 11,2 & 1.1 & 1.7 & 1,6 & 1.2 & () & 9.5 & 0 \\
\hline EXGOR4/E2-5 & General & 4,5 & 4,8 & 66,2 & 5,6 & 0,85 & 0,66 & 1,2 & 0.86 & 0 & 15.1 & 0.24 \\
\hline EXGOR5/E2-1 & Grano gris & 3,4 & 10,1 & 61,6 & 3,3 & 0 & 12.2 & 1.9 & () & () & 6.5 & 0.87 \\
\hline EXGOR5/E2-2 & Matriz gris clara & 5,4 & 11 & 61,6 & 6,2 & 1,61 & 8.7 & 2,4 & 0 & 0 & 3 & 0 \\
\hline EXGOR5/E2-4 & General & 3,1 & 8,8 & 68,8 & 3,8 & 1,4 & 4,1 & 2,3 & 0 & () & 7,8 & 0 \\
\hline EXGOR5/E3-7 & Matriz & 3,4 & 11 & 71,61 & 6,5 & 1,7 & 0 & 4 & 1.1 & 0 & 0.6 & 0 \\
\hline EXGOR5/E3-8 & General & 2,7 & 8,4 & 73,3 & 3,7 & 1 & 0 & 2.7 & 0.9 & () & 7.2 & 0 \\
\hline EXGOR5/E4-4 & Matriz) & 4,6 & 13,4 & 64,3 & 4 & 1,6 & 0 & 3,1 & 1,6 & 0 & 7,4 & 0 \\
\hline EXGOR5/E4-5 & General & 2,5 & 8,3 & 71,5 & 2,5 & 0,97 & 1,6 & 2,2 & 0.39 & () & 10 & 0 \\
\hline
\end{tabular}

Tab. 9. Análisis de escorias experimentales de Gorny (Microsonda MEB, \% en peso de óxidos).

recuperable. Esta afirmación vale, claro está, para los procesos de fundición sin escorificación ni separación de metal como el practicado en Gorny.

En el experimento $\mathrm{n}^{\circ} 5 \mathrm{se}$ fundieron $3 \mathrm{~kg}$ de mineral, con un consumo de carbón de $6 \mathrm{~kg}$ (incluyendo la fase de precaldeo del horno). La escoria resultante fue triturada y lavada con agua en una batea para separar por diferencia de densidades el cobre metálico, obteniéndose $110 \mathrm{~g}$ de metal. Esto significa un rendimiento del $3,7 \%$ en peso en relación con el mineral. Considerando que el mineral contenía $207 \mathrm{~g}$ de cobre $(6,9 \% \mathrm{Cu})$, el rendimiento neto de la extracción es del $53,1 \%$, cifra real nada despreciable, superior al $25 \%$ obtenido por Zwicker (1980: 15) con los minerales de Norsun-Tepe.

Conviene traer a colación los experimentos de fundición realizados por Lorenzen (1966) con minerales de cobre encajados en arenisca de Heligoland, en los que consiguió obtener bolitas de cobre con un peso total equivalente al 5,6\% del mineral empleado, algo superior al obtenido por nosotros. Pero conviene puntualizar que Lorenzen utilizó medios de laboratorio para la trituración y recuperación del cobre, mientras que nosotros usamosprocedimientos muy similares a los prehistóricos y, por tanto, con mayor probabilidad de pérdidas. 


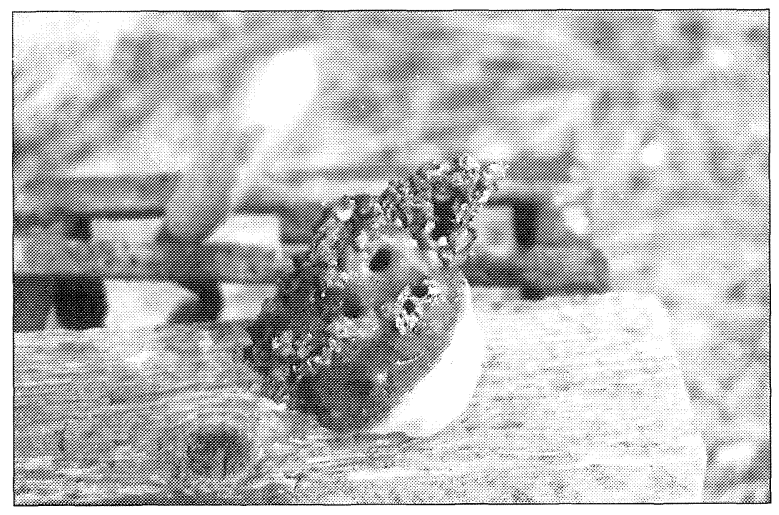

Lám. XVII. Extremo de la boquilla de una tobera de arcilla, fundido como consecuencia de las elevadas temperaturas conseguidas en el hogar del horno. Experimento $n^{\circ} 4$.

\section{HACIA UN MODELO TEÓRICO DE LA EXPLOTACIÓN DE RECURSOS NATURALES EN KARGALY}

La arqueometalurgia experimental junto con los datos objetivos de la arqueología de campo han proporcionado información que nos permiten esbozar unos modelos de interés económico con los que evaluar la producción de cobre en Kargaly.

Parece evidente que los hornos empleados fueron estructuras muy sencillas apenas reconocibles, y existían espacios concretos para las prácticas metalúrgicas en las viviendas-taller. Pero no tenemos la completa seguridad de que la vía experimental reproduzca fielmente el proceso metalúr-gico prehistórico. De hecho sabemos que en las fundiciones prehistóricas se lograba separar por gravedad algo de metal, aunque suponemos que no sería demasiado dada la elevada viscosidad de la escoria, cosa que en los experimentos no conseguimos (16). Sin embargo, tanto nuestros resultados experimentales como los de otros colegas indican que la mayor parte del cobre producido permanecía embebido en la escoria como pequeñas bolitas metálicas, como sucede en las arqueológicas.

El mineral extraído de las minas debía ser seleccionado y machacado hasta porciones pequeñas, de

(16) El Dr. Chernyh nos ha informado de un experimento realizado por uno de los colaboradores de la excavación, Nikola, de la aldea de Maximovsky, después de nuestra partida de Kargaly en 1998. Construyó un horno de chimenea con ladrillos y bloques prefabricados, de $1,5 \mathrm{~m}$ de altura, con tiro natural, y consiguió separar de la escoria una masa de cobre de unos $50 \mathrm{~g}$. Desconocemos las características de la carga y las condiciones del trabajo de dicho horno. unos pocos milímetros, antes de ser cargado en el horno. No tenemos datos en términos trabajador/ hora de lo que podría costar la extracción de mineral, pero sí los tenemos acerca de lo que costó la trituración: 2,5 horas, tres personas, para triturar 6 $\mathrm{kg}$ de fragmentos de mineral recogido previamente en superficie (1,5 hombres/hora/kg de mineral). Como sólo se emplearon $3 \mathrm{~kg}$ el valor real es la mitad. Esta cifra y otras que se manejarán más adelante podrían reducirse si tenemos en cuenta que las tareas experimentales fueron realizadas por personas no especialmente adiestradas.

En los cinco experimentos efectuados, la fundición propiamente dicha ocupó entre 2 y 4 horas, a las que hay que añadir algo más de media hora de precalentamiento del horno. Dado que en todos los experimentos se obtuvo una masa de escoria de características similares, puede tomarse la cifra de 3 horas como tiempo normal de reducción (17). La escoria correspondiente a $3 \mathrm{~kg}$ de mineral fue triturada por tres personas trabajando durante 2 horas (1,3 personas/hora/kg de escoria), obteniéndose tras el lavado $110 \mathrm{~g}$ de cobre en granos.

Este cobre fue refundido en un crisol, en una hornilla con un kilo de carbón aproximadamente (18), ventilada con dos fuelles, empleando en esta operación unos 30 minutos dos personas (19). El resultado fue un lingote planoconvexo de $90 \mathrm{~g}$, con el restante cobre en forma de bolitas pegadas a las paredes del crisol (Lám. XVIII).

En resumen, sin contar la extracción del mineral, las distintas operaciones sucesivas pueden ser ejecutadas por 2-3 personas en unas ocho horas. Racionalizando tiempos y movimientos es posible obtener unos $200 \mathrm{~g}$ de cobre en ese tiempo (20), contando con minerales como los usados en los experimentos.

El consumo de carbón puede fijarse en $13 \mathrm{~kg}$, lo que supone $65 \mathrm{~kg}$ por kilo de cobre en lingote. Para conseguir dicho carbón serían necesarios, en las condiciones más desfavorables, unos $500 \mathrm{~kg}$ de madera seca (Horne, 1982) (21).

(17) En los experimentos de Lorenzen (1966: 16) se emplearon 4 horas, con una hora de caldeo.

(18) Operación realizada Por J. Happ y el autor.

(19) Entre la introducción del crisol en la hornilla y su extracción con el cobre fundido transcurrieron unos 15 minutos.

(20) Fundir los otros $3 \mathrm{~kg}$ de mineral, con el horno a pleno rendimiento, hubiera tomado 1,5 horas más.

(21) Este autor ha calculado que la proporción en peso madera/carbón oscila entre $5 / 1$ y $7 / 1$. Asimismo, establece que para obtener un kilogramo de metal son necesarios unos $40 \mathrm{~kg}$ de carbón, cifra bastante concordante con la obtenida por nosotros si le añadimos el carbón necesario para obtener el lingote. 


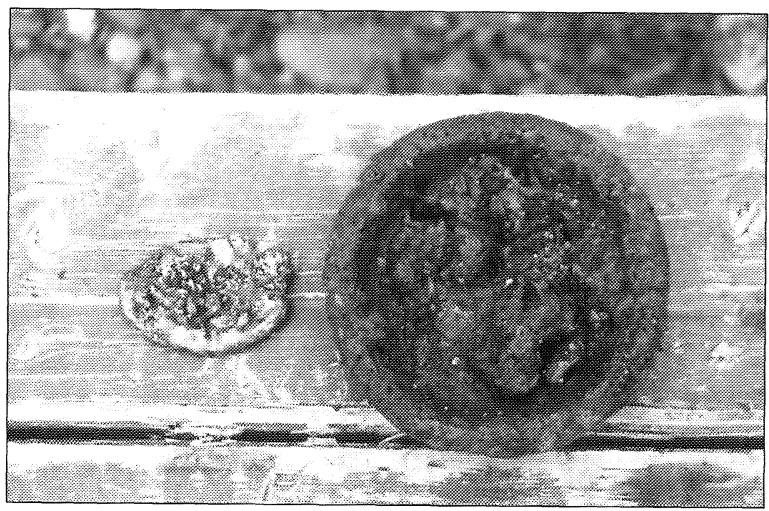

Lám. XVII. Lingote planoconvexo de cobre y crisol en el que fue obtenido.

Eugen N. Chernykh (1998: 72) ha propuesto la producción de unas $150.000 \mathrm{Tm}$ de cobre a lo largo de la Edad del Bronce, lo cual supondría la tala de árboles equivalente a 75.000.000 Tm de made$\mathrm{ra}$, una cifra verdaderamente escalofriante que ha dado lugar a que nos preguntáramos en más de una ocasión si la metalurgia prehistórica no habría provocado una catástrofe ecológica con una deforestación intensiva que llegó a colapsar esta actividad a finales del Bronce, convirtiendo una comarca boscosa en la estepa que ahora conocemos.

Llegados a este punto, buscar un modelo explicativo no resulta fácil pues hay más carencias de información que datos prácticos. Desconocemos el grado de explotación de los recursos minero-metalúrgicos a lo largo del Calcolítico y la Edad del Bronce y la densidad de ocupación del territorio. Si nos atenemos a un modelo lineal, poco creíble, y consideramos que la explotación tuvo lugar a lo largo de 2.000 años, la producción de cobre sería de $75 \mathrm{Tm} /$ año y el consumo de madera de $37.500 \mathrm{Tm} /$ año, una cifra que no parece soportable por la población arbórea actual (suponiendo que fuera similar a la prehistórica), lo que implicaría considerar una masa forestal mayor en el pasado que habría sido esquilmada por la metalurgia, o la importación de madera de otras latitudes.

Quizás fuera más acertado actuar a la inversa, partiendo de la realidad arqueológica. La excavación de Gorny ha desenterrado un complejo que parece ser una vivienda unifamiliar o, en todo caso, de un pequeño grupo, con un solo patio de fundición, es decir, que la actividad metalúrgica se realizaba en un solo lugar. Si esta interpretación es acertada, el grupo se ocupaba de todas las actividades inherentes al proceso: mine- ría (22), fundición de minerales, fabricación de lingotes y producción de objetos de metal, pues de todas ellas hay pruebas en el registro. Dando por buenos los resultados experimentales, en esa vivienda no se debían producir más allá de 200 ó 300 g. de cobre por hornada. Suponiendo que el horno trabajara todos los días del año, cosa poco probable porque debían realizarse otras tareas en el banco de fuego, podemos calcular, siendo generosos, unos 100 $\mathrm{kg}$. de cobre al año por familia o taller. Esta instalación consumiría unas $50 \mathrm{Tm}$ de madera al año para producir el carbón necesario para fundir del orden de 3 Tm de mineral.

El complejo de Gorny estuvo en activo, según los cálculos efectuados a partir de las fechas radiocarbónicas, entre 1690 y 1410 BC (Chernyj et alii, 1999: 98-99, Tab. 7), es decir, unos 300 años. Sin embargo, la cantidad de hallazgos metalúrgicos en cada una de las cuatro fases es muy distinto, como muestra la figura 7. Es interesante hacer notar la coincidencia entre hallazgos metálicos y moldes, lo que otorga cierta confianza a su valor como modelo. En función de estos datos podemos suponer una producción metalúrgica poco intensa (en términos relativos) al comienzo, que crece considerablemente en la Fase B-1, pasa por un tiempo de crisis en la B-2 y vuelve a crecer espectacularmente en la última fase de Gorny. Así, pues, siguiendo las sugerencias de la figura 7 podríamos dividir la producción global del taller según los coeficientes de proporcionalidad 1,9,31, 12,4 y 54,7 . Si antes habíamos calculado una producción estimada en $100 \mathrm{~kg}$ de cobre al año como dato más favorable para la vivienda (Fase B-2), a la Fase A le corresponderían $6,1 \mathrm{~kg} / \mathrm{año}$, a la B-1 $100 \mathrm{~kg} / \mathrm{año}$, a la B-2 40 kg/año y a la B-3 176,5 kg/año. Hacer el cálculo estimativo del consumo de leña durante todo el período es ya un simple problema aritmético que arroja la cifra de 10.700 Tm en 300 años. Se habrían extraído de las minas $640 \mathrm{Tm}$ de mineral, de las que habrían salido $21,4 \mathrm{Tm}$ de cobre en lingotes.

La primera pregunta que cabe hacerse es si el entorno de Gorny podía proporcionar la madera necesaria. Si el paisaje arbóreo en el Bronce Final era similar al actual, como parecen indicar los estu-

(22) No hay duda de que los habitantes de Gorny conocían las artes de la minería. La propia casa cuenta con una galería sacra excavada en el subsuelo (véase la figura 4) pero, además, a pocos metros se ha localizado una zanja profunda, antigua, que podría ser una rampa de descenso a una bocamina o a una explotación a cielo abierto.

T. P., 56, n. ${ }^{\circ} 2,1999$ 


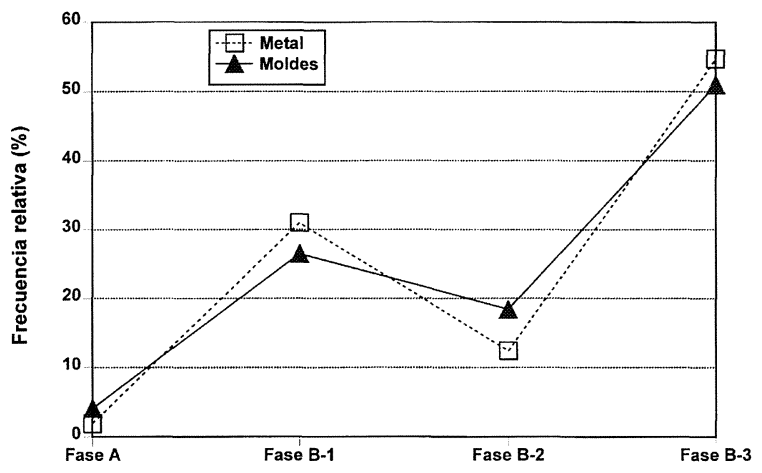

Fig. 7. Representación gráfica de los restos metálicos y los moldes según las fases culturales de Gorny. Datos tomados de Chernykh et alii (1999: 95, Tab. 4 y 96, Tab. 5).

dios polínicos (23), resulta razonable pensar que, al menos desde la Fase B-1, fue necesario traer madera de las zonas boscosas situadas más al norte, actualmente a más $200 \mathrm{~km}$ de distancia pero quizás algo más cercanas entonces. Hay un indicio que permite apoyar esta suposición: el progresivo aumento de la presencia de caballo adulto entre los huesos del yacimiento, como ha identificado Antipina (1999: 104). Los datos osteológicos, medidos con el mismo parámetro que los restos metálicos, están representados en la figura 8 , en la que puede apreciarse un ritmo de crecimiento de la cabaña equina con pautas semejantes a la supuesta producción metalúrgica, en especial en el último tramo, que es también el de mayor intensificación de las fundiciones.

Los coeficientes de proporcionalidad que hemos manejado antes permiten otras interpretaciones del fenómeno metalúrgico. Dado que la tecnología empleada para la fundición de minerales es tan sencilla y no parece cambiar substancialmente a lo largo de las distintas fases, podemos asumir que el rendimiento de los hornos se mantuvo prácticamente constante. Los coeficientes mencionados serían también un indicador de la intensidad de la producción y, en otros términos, de la densidad de asentamientos.

Volviendo a la estimación de Chernyj, y suponiendo que de las $150.000 \mathrm{Tm}$ de cobre producidas en el Bronce Final sólo 100.000 lo fueran en el pe-

(23) Se encuentra en avanzado proceso de elaboración un trabajo de Vicent, J.M.; Rodríguez Alcalde, A.L.; López Sáez, J.A.; Zavala, I.; López García, P. y Martínez Navarrete, M.I “Catástrofes ecológicas en la estepa? Arqueología del paisaje en el complejo minero-metalúrgico de Kargaly (Región de Orenburg, Rusia)", cuya publicación está prevista en el próximo número de Trabajos de Prehistoria, 57(1). En él se expondrán con detalle los estudios a los que nos referimos.

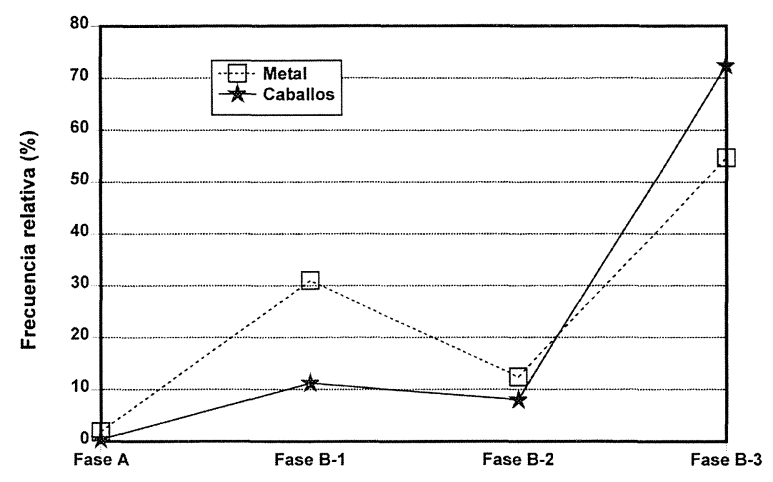

Fig. 8. Gráfico comparativo de restos metálicos y cabaña equina. Datos tomados de Chernykh et alii (1999: 95, Tab. 4 y 96, Tab. 5) y Antipina (1999: 105, Tab. 1).

ríodo Srubnaia, utilizando el modelo de Gorny corresponderían 1.900 a la Fase A, 31.000 a la B-1, 12.400 a la B-2 y 53.100 a la B-3. Para alcanzar estas cifras sería necesario que un determinado número de hornos estuviera operando a diario en cada fase. Las cifras resultantes serían: Fase A, 190 hornos durante 100 años; Fase B-1, 3.100 hornos durante 100 años; Fase B-2, 2.480 hornos durante 50 años; Fase B-3, 10.600 hornos durante 50 años.

Estas cifras sugieren, a pesar de la rigidez del modelo, un progresivo aumento de la población minero-metalúrgica según una función exponencial, con una explotación de baja intensidad (en términos relativos) en los dos milenios largos que preceden al Bronce Final, que se intensifica a partir de la Fase B-1 de Gorny. Aunque no disponemos de datos sobre la densidad de los asentamientos, las dificultades para localizarlos mediante la prospección realizada sería indicio de una baja densidad de ocupación en la extensa área de $800 \mathrm{~km}^{2}$ que ocupa la cuenca minera que, en su fase más productiva, no pasaría de 14 hornos $/ \mathrm{km}^{2}$. El asentamiento de Gorny sugiere, efectivamente, un hábitat disperso e independiente, pero ignoramos hasta qué punto se atiene a una norma de poblamiento o es excepcional. Nuevas campañas de prospección y las correspondientes excavaciones permitirán establecer un panorama mejor definido.

En cualquier caso, la producción de cobre propuesta por Chernyj parece razonable a la vista de los modelos que pueden establecerse a partir de la metalurgia experimental.

Otra posible interpretación que ya fue sugerida por Chernykh (1994) es que la actividad metalúrgica local no fuera demasiado importante, dedicada principalmente a la producción de herramientas 
para el laboreo de las minas, funcionando quizás a expensas de la escasa reserva arbórea del entorno. Sería la actividad minera la de mayor intensidad, generando una extensa red de distribución de mineral en torno a Kargaly. Esta hipótesis explicaría una carencia preocupante, los escoriales, al tiempo que, en términos ponderales, resultaría menos gravoso exportar el mineral que importar la leña. Es, por otro lado, una hipótesis fácil de confirmar dadas las peculiaridades de los minerales de la zona. Sería necesario, eso sí, localizar y excavar otros poblados alejados de la cuenca minera, efectuando los estudios arqueometalúrgicos pertinentes.

El transporte de minerales de Kargaly hacia las zonas boscosas de los Urales (a 250-300 km de distancia) dio lugar a una floreciente industria del cobre en Bashkiria a lo largo de los siglos XVIII y XIX AD. Por los datos históricos que conocemos, no parece que los medios de transporte empleados en la Edad Moderna (caballerías, carros y trineos) fueran muy diferentes de los disponibles en la Edad del Bronce. Es, por tanto, un modelo de producción que no debemos rechazar de antemano.

\section{AGRADECIMIENTOS}

Muchas personas han colaborado activamente, allá en Rusia, para que nuestro trabajo fructificara. Del Dr. Chernyj obtuvimos todo el apoyo logístico que necesitamos, amén de contrastes de ideas e informaciones valiosísimas, y con los años, una sincera amistad. La actitud de todos los miembros de su equipo, Tamara O. Teneishvili, Ekaterina E. Antipina, Sergei V. Kuzminyj, HelenaYu. Levedeva, Vladimir Yu. Lunkov, Sergei V. Bikov "Sturmann", Denis V. Valkov y Alexei Karpujin ha sobrepasado con mucho la relación estrictamente profesional. De la recogida de mineral para los experimentos se ocuparon diligentemente Galina Nikoforova y sus chicas y chicos del campo de trabajo, y pude contar con la ayuda directa de varios de ellos coordinados por Ilia Plotnikov en las tediosas tareas de machacar el mineral y accionar los fuelles. En la última parte experimental se incorporaron Jacques Happ y Marie-Chantal Frère-Sautot (de la APAB, Arqueódromo de la Borgoña, Francia). En lugar preferente debo mencionar a Maribel Martínez Navarrete, Investigadora Principal del proyecto español, paciente, eficaz y minuciosa gestora de los innumerables trámites que todavía exige la entrada, desplazamiento y salida de Rusia de personas y pertrechos, además de excelente compañera de fatigas en los trabajos de campo. Sin Maribel habría sido otra cosa o, sencillamente, no habría sido...

\section{BIBLIOGRAFÍA}

AMBERT, P. (1998): “Métallurgie préhistorique, métallurgie expérimentale, les fours, état de la question, perspectives de recherches". En M.-Ch. Frère-Sautot (ed.): Paléométallurgie des cuivres. Actes du colloque de Bourg-en-Bresse et Beaune, 17-18 oct. 1997. Éditions Monique Mergoil. Montagnac: 1-16.

Antipina, Ye.Ye. (1999): "Restos óseos de animales en el poblado Gorny. (Aspectos biológicos y arqueológicos de la investigación)". Arqueología Rusa, 1: 103-116 (en ruso).

BaCHMANN, H.G. (1982): The identification of slags from archaeological sites. Institute of Archaeology. London.

CHERnIJ, E.N. (1995): "Kargali. La energía de producción y las catástrofes ecológicas”. Revista de Arqueología, 168: 30-35.

Chernyj, Ye.N.; KuZminyu, S.V.; LebedeVa, Ye.Yu.; Agapov, S.A.; LunKov, V.Yu.; Orlovskaia, L.B.; Teneishvili, T.O. y VALKOV, D.V. (1999): "Yacimientos arqueológicos de la Edad del Bronce en Kargaly (el poblado Gorny y otros)". Arqueología Rusa, 1: 77-102 (en ruso).

ChERNYKH, E.N. (1994): "L'ancienne production minière et métallurgique et les catastrophes écologiques anthropogènes: introduction au problème". Trabajos de Prehistoria, 51(2): 55-68.

- (1998): "Kargaly, le plus grand ancien complexe minier et de métallurgie à la frontière de l'Europe et de l'Asie". En M.-Ch. Frère-Sautot (ed.): Paléométallurgie des Cuivres. Actes du colloque de Bourg-en-Bresse et Beaune, 17-18 oct. 1997. Éditions Monique Mergoil. Montagnac: 71-76.

Chernykh, E.N. y Rovira, S. (1998): "La metalurgia antigua del cobre en Kargali (Orenburg, Rusia): informe preliminar”. En M.-Ch. Frère-Sautot (ed.): Paléométallurgie des Cuivres. Actes du colloque de Bourg-enBresse et Beaune, 17-18 oct. 1997. Éditions Monique Mergoil. Montagnac: 77-83.

Chibilev, A.A. (1996): El patrimonio natural de la región de Orenburg. Editorial de Libros de Orenburg. Orenburg (en ruso).

FLuZiN, P. (1983): «Notions élémentaires de sidérurgie». En N. Echard (ed.): Métallurgies Africaines. Nouvelles contributions. Société des Africanistes. París: 13-44.

Gómez Ramos, P. (1999): Obtención de metales en la Prehistoria de la Península Ibérica. BAR International Series, 753. Oxford.

Hauptmann, A. (1989): "The earliest periods of copper metallurgy in Feinan/Jordan". En A. Hauptmann, E. Pernicka y G.A. Wagner (eds.): Archäometallurgie der

T. P., 56, n. ${ }^{\circ} 2,1999$ 
Alten Welt/Old World Archaeometallurgy. Der Anschnitt, 7: 119-135.

Hauptmann, A.; Bachmann, H.G. y Maddin, R. (1996):

"Chalcolithic copper smelting: new evidence from excavations at Feinan, Jordan". Archaeometry 1994, Ankara. The Proceedings of the $29^{\text {th }}$ International Symposium on Archaeometry. Ankara, 9-14 May 1994. Tübitak. Ankara: 3-10.

HoRnE, L. (1982): "Fuel for the metal worker". Expedition, 25 (1): 6-13.

LORENZEN, W. (1966): "Notes concerning copper smelting". Bulletin of the Historical Metallurgy Group, 7: 13-21.

ROTHENBERG, B. (1985): "Copper smelting furnaces in the Arabah, Israel: The archaeological evidence". En P.T. Craddock y M.J. Hugues (eds.): Furnaces and Smelting Technology inAntiquity. British Museum Occasional Paper, 48: 123-150.

RoviRA, S. (1989): "Recientes aportaciones para el conocimiento de la metalurgia primitiva en la provincia de Madrid: Un yacimiento Campaniforme en Perales del Río (Getafe, Madrid)". Actas del XIX Congreso Nacional de Arqueología (Castellón, 1987). I: 355-366. Zaragoza.
- (1992): «Arqueometalurgia».En G. Ripoll(ed.):Arqueología, hoy. Cuadernos de la UNED, 108. Universidad Nacional de Educación a Distancia. Madrid: 221-227.

Tylecote, R.F.; Ghaznavi, H.A. y Boydell, P.J. (1977): «Partitioning of trace elements between the ores, fluxes, slags and metal during the smelting of copper». Journal of Archaeological Science, 4: 305-333.

TYLeCOTE, R.F. y MERKEL, J.F. (1985): "Experimental smelting techniques: Achievements and future". En P.T. Craddock y M.J. Hughes (eds.): Furnaces and Smelting Technology in Antiquity. British Museum Occasional Paper, 48: 3-20.

ZwICKER, U. (1980): "Investigations on the extractive metallurgy of $\mathrm{Cu} / \mathrm{Sb} / \mathrm{As}$ ore and excavated smelting products from Norsun-Tepe (Keban) on the upper Euphrates (3500-2800 BC)". En W.A. Oddy (ed.): Aspects of Early Metallurgy. British Museum Occasional Paper, 17: 13-26.

ZWICKER, U.; ViRDIS, P. y CERUTI, M.L. (1980): "Investigations on copper ore, prehistoric copper slag and copper ingots fron Sardinia". En P.T. Craddock (ed.): Scientific Studies in Early Mining and Extractive Metallurgy. British Museum Occasional Papers, 20: 135-163. 